\title{
La preservación de los espacios agrofluviales urbanos como reto paisajístico: un análisis comparativo de Lleida, Girona y Perpinyà a partir de los instrumentos de planificación*
}

\author{
Sylvain Rode \\ Université de Perpignan \\ sylvain.rode@univ-perp.fr
}

\author{
Albert Santasusagna Riu \\ Joan Tort Donada \\ Maria Teresa Vadrí Fortuny \\ Universitat de Barcelona \\ asantasusagna@ub.edu \\ jtort@ub.edu \\ mtvadri@ub.edu
}

\section{Resumen}

En el presente artículo se lleva a cabo un estudio comparativo de tres ejemplos de paisaje agrario patrimonial que, más allá de sus diferencias en cuanto a características y extensión, se sitúan en unos contextos de transición urbano-rural similares: la extensa Horta de Lleida, en el curso bajo del río Segre; las Hortes de Santa Eugènia, junto a los ríos Onyar y Ter en Girona, y los Horts de Sant Jaume, en Perpinyà, vinculados al río Tet. A partir del análisis de los instrumentos de planificación urbana que, en cada caso, les han afectado, trazamos una síntesis de su evolución a lo largo de los últimos 70 años como espacios agrarios enmarcados en una trama urbana y vinculados a un curso fluvial. Como corolario, planteamos en qué medida es posible llevar a cabo en ellos una gestión que concilie su funcionalidad con la preservación de su valor histórico y patrimonial.

Palabras clave: ordenación de los espacios agrarios; interfaz urbano-rural; entornos fluviales urbanos; planeamiento urbanístico; ciudades medias

* La realización de este artículo ha sido posible gracias al desarrollo del proyecto científico postdoctoral concertado entre la Universidad de Barcelona y la Sociedad General de Aguas de Barcelona (AGBAR). Se inscribe, asimismo, en el marco del proyecto CSO2015-6787C6-4-P, del Ministerio de Economía y Competitividad del Gobierno de España, y en su momento contó también con el apoyo de la Generalitat de Catalunya (2017SGR1344, Grup de Recerca Ambiental Mediterrània). 
Resum. La preservació dels espais agrofluvials urbans com a repte paisatgístic: una anàlisi comparativa de Lleida, Girona i Perpinyà a partir dels instruments de planificació

En aquest article es duu a terme un estudi comparatiu de tres exemples de paisatge agrari patrimonial que, més enllà de les seves diferències en relació amb característiques i extensió, se situen en uns contextos de transició urbanorural similars: l'extensa Horta de Lleida, al curs baix del riu Segre; les Hortes de Santa Eugènia, prop dels rius Onyar i Ter a Girona, i els Horts de Sant Jaume, a Perpinyà, vinculats al riu Tet. A partir de l'anàlisi dels instruments de planificació urbana que, en cada cas, els han afectat, duem a terme una síntesi de l'evolució que han sofert al llarg dels últims 70 anys com a espais agraris emmarcats en una trama urbana i vinculats a un curs fluvial. Com a corol-lari, plantegem en quina mesura és possible dur a terme una gestió que sigui capaç de conciliar-ne la funcionalitat amb la preservació del seu valor històric i patrimonial.

Paraules clau: ordenació dels espais agraris; interfície urbanorural; entorns fluvials urbans; planejament urbanístic; ciutats mitjanes

Résumé. La préservation des espaces agrofluviaux urbains en tant que défi paysagistique: analyse comparative de Lleida, Girona et Perpignan à partir des instruments de planification

Cet article propose une analyse comparative de trois études de cas partageant des caractéristiques paysagères similaires (les vergers connus comme Horta de Lleida, autour du fleuve Segre; Hortes de Santa Eugènia, à Girona, le long du Ter, et les Horts de Sant Jaume à Perpignan, liés au fleuve Têt) dans le but de comprendre les principaux changements, analogies et différences qui ont conduit à leur stabilisation actuelle en tant qu'espaces agraires historiques insérés dans une parcelle urbaine et liés à un fleuve. Notre contribution porte sur l'analyse de la planification urbaine générée au cours des soixante-dix dernières années, dans le but de connaître la vision de ces espaces de la part de l'administration et, parallèlement, de vérifier leur fonctionnalité et leur dynamique par rapport à l'ensemble urbain. En corollaire, nous nous demandons dans quelle mesure il est possible d'y mener une gestion préservant leur valeur historique et patrimoniale.

Mots-clés: aménagement d'espaces agricoles; interface urbaine-rurale; environnements fluviaux urbains; planification urbaine; villes moyennes

Abstract. The preservation of urban agrofluvial spaces as a landscape challenge: A comparative analysis of Lleida, Girona and Perpinyà based on planning instruments

This paper presents a comparative analysis between three case studies that share similar landscape characteristics (the Horta de Lleida on the Segre River, the Hortes de Santa Eugènia beside the Ter River in Girona and the Horts de Sant Jaume in Perpinyà linked to the Tet River). The aim of the analysis is to understand the main changes, analogies and differences that have led to their current stabilization as historical and rural spaces inserted in an urban setting and linked to a watercourse. Additionally, we examine urban planning processes undertaken in the last seventy years to determine the administration's vision of these spaces and, at the same time, discuss their functionality and dynamics in relation to urban space. As a corollary, we propose the extent to which it is possible to manage these spaces with a view to preserving their historical and heritage value.

Keywords: rural spatial planning; urban-rural interface; urban-river spaces; urban planning; mid-sized cities 


\section{Sumario}
1. Introducción
4. Resultados
2. Objetivos, metodología
5. Discusión y conclusiones
y fuentes utilizadas
Referencias bibliográficas

3. Caracterización general de los ámbitos de estudio

\section{Introducción}

La gestión del territorio emerge como una herramienta necesaria a la hora de acotar políticas concretas y específicas que basen sus objetivos en la continuidad, sostenibilidad y dinamización del paisaje, más allá de su protección a través de varias figuras legales (Mata, 2004; Mata y Tarroja, 2006; Zoido, 2010; Paül et al., 2011). Dentro del contexto de las políticas de gestión, las medidas de dinamización económica del paisaje se presentan, también, como instrumentos efectivos a la hora de potenciar sus valores sociales y patrimoniales y, por lo tanto, asegurar su continuidad (Llop, 2011; Molinero, 2011; Gómez Mendoza, 2013; Corbera, 2016; Silva y Fernández, 2017). No obstante, en numerosos casos la necesidad de aprovechar los recursos económicos presentes en el paisaje ha conducido a su paulatina degradación, hecho que ha repercutido directamente en una disminución o en un abandono de ciertos usos históricamente protagonistas, como el agrícola (Andrés, 2004; Paül, 2010; De Santiago, 2012; Sancho et al., 2013).

La aplicación de las políticas públicas de paisaje en el contexto europeo $y$, particularmente, en el español, ha sido esencial a la hora de abordar sus problemáticas presentes y sus retos futuros (Zoido, 2001; Frolova et al., 2003; Serrano, 2007; Nogué, 2010a). La visión técnico-política del paisaje por parte de la Administración pública - y, subrayamos, técnica por una parte y política por otra - ha condicionado escenarios y situaciones muy distintas por toda la geografía española (figura 1). El desconocimiento de la realidad del paisaje, así como una ausencia de voluntad política a la hora de gestionarlo a partir de instrumentos y herramientas efectivos, ha conducido a escenarios de degradación que, en algunos casos, han sido difíciles de revertir (Galacho-Jiménez y LuqueGil, 2000; Ibarra et al., 2011; Matarán Ruiz, 2013; Lasanta et al., 2013). La pérdida de espacio agrícola y su lucha incesante con la presión urbanizadora, así como los efectos derivados del abandono rural, son las principales causas de este escenario negativo.

Por otra parte, el conocimiento técnico del paisaje tampoco ha sido suficiente, en muchos casos, para encauzar la recuperación de sus valores sociales, históricos, económicos y patrimoniales. La simple protección del paisaje, sin una estrategia de dinamización socioeconómica para fomentar actividades humanas básicas para su continuidad — como pueden ser, por ejemplo, las actividades ligadas al mundo rural-, no es suficiente para asegurar su per- 
Figura 1. La visión técnico-política y sus consecuencias en la gestión de los paisajes patrimoniales de dominante agraria

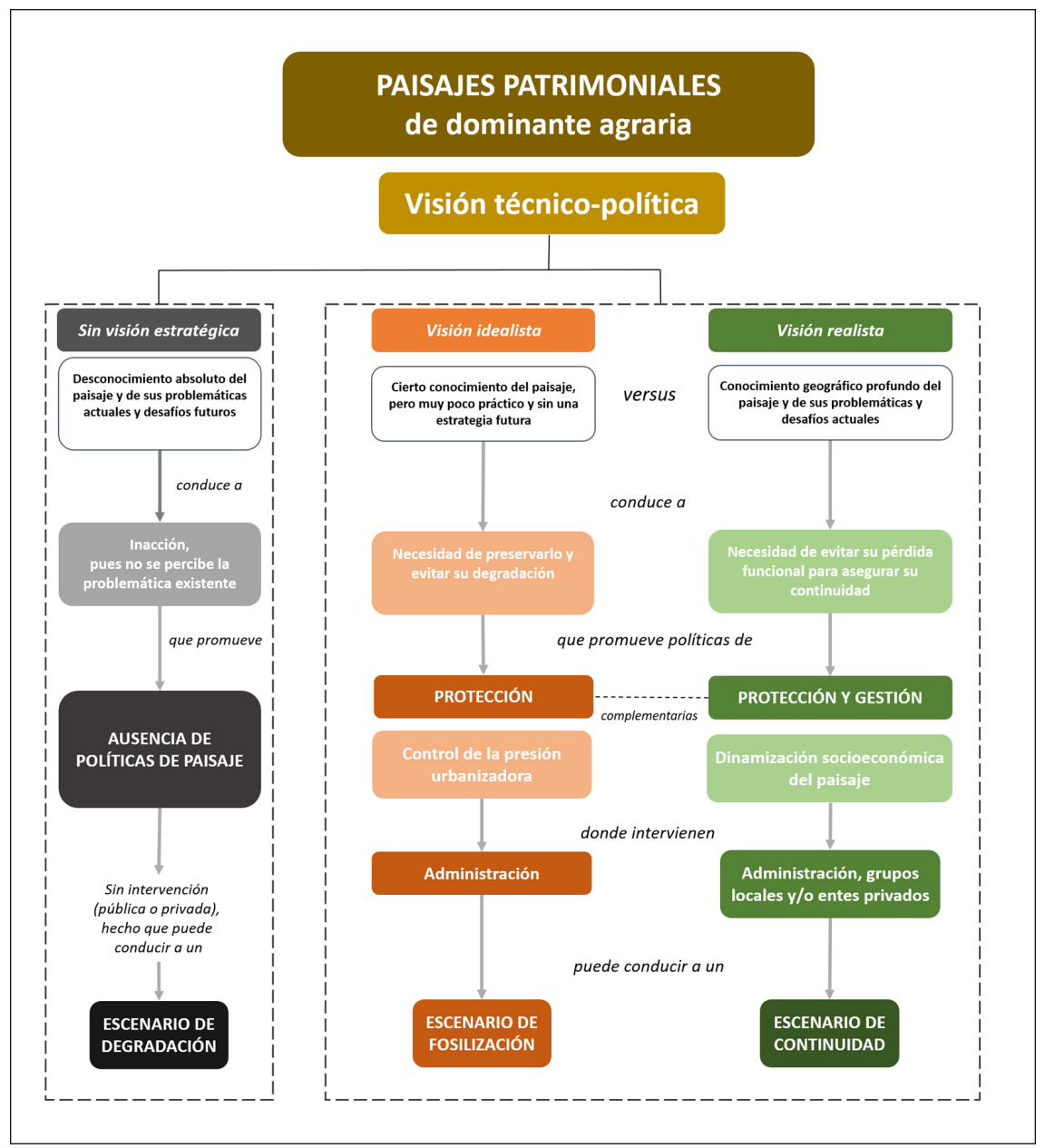

Fuente: elaboración propia.

vivencia y su evolución en el tiempo. Esta actitud preservacionista por parte de la Administración — que puede calificarse, también, como idealista, en la medida en que confía en la protección como única solución general a los retos paisajísticos - lleva a lo que numerosos autores conocen como fosilización del paisaje (Tarroja, 2006; Hernández y Morales, 2012), una etapa que puede ser, en determinados casos, previa a la degradación. La protección puede representar un primer paso hacia la recuperación del paisaje, pero debe ir acompañada 
de una serie de actuaciones específicas y orientadas a su continuidad en el espacio y en el tiempo.

Finalmente, una visión técnico-política realista, con un conocimiento profundo del paisaje y de sus principales problemáticas, así como la elaboración de una estrategia de actuación bien definida — con objetivos a corto, medio y largo plazo-, puede comportar un refuerzo de la identidad territorial y, a su vez, una recuperación de actividades históricas fundamentales para su continuidad (Prada, 2005; Nogué, 2007, 2010b). En el caso de los paisajes patrimoniales de dominante agraria, estas actuaciones pueden encaminarse, por ejemplo, a la implementación de proyectos agrourbanos de ámbito territorial (Vidal y Fleury, 2009; Paül y Haslam, 2013), permitiendo así satisfacer la demanda social de productos orgánicos y locales, así como el desarrollo de itinerarios y de recorridos para su conocimiento público (Torre y BordeauLepage, 2013).

\section{Objetivos, metodología y fuentes utilizadas}

La presente investigación tiene como objetivo principal analizar, de forma comparativa, tres casos de estudio de paisaje agrofluvial que están vinculados a ciudades mediterráneas de tipo medio emplazadas en una latitud equiparable. Hablamos, concretamente, de tres espacios de producción hortícola dentro de un marco parecido que cabe calificar de periurbano y que, más allá de sus diferentes dimensiones y de su grado de tradición, pueden ser considerados en todos los casos como unos ámbitos plenamente arraigados al respectivo territorio en el que se insieren. Se trata de la extensa Horta de Lleida, en el curso bajo del Segre y centrada por la ciudad que le da nombre; de la zona hortícola conocida como Hortes de Santa Eugènia, en los aledaños del río Ter en Girona, y, finalmente, del ámbito conocido como Horts de Sant Jaume, junto al río Tet, en Perpinyà) ${ }^{1}$.

A tal efecto, las fuentes principales de este estudio son los planes urbanísticos aprobados por los consistorios municipales (de Lleida, Girona y Perpinyà) desde la década de 1950 hasta la actualidad (tabla 1). Estos documentos han sido consultados con la intención de recoger, analizar e interpretar las intervenciones proyectadas en los respectivos territorios de referencia. Hemos analizado cinco planes sobre Lleida - cuatro de ámbito general y uno de carácter especial — y seis relativos a Girona — cinco de ámbito general y uno de especial-. En el caso de Perpinyà, hemos analizado seis planes; concretamente, cinco documentos correspondientes a la planificación municipal y un documento sobre planificación urbana intercomunal. Los describimos con detalle en la propia tabla 1.

1. En la medida en que, en los tres ámbitos estudiados, más allá de su adscripción política a dos Estados diferentes, hay una cultura catalana común, hemos optado por escribir los nombres de lugar en su forma catalana, dejando al margen el hecho de que puedan existir formas exonímicas en francés o en castellano para referirse a ellos. 
Tabla 1. Relación del planeamiento urbano analizado en cada caso de estudio. El asterisco (*) señala la planificación de carácter especial

\begin{tabular}{|c|c|c|c|}
\hline Concepto & Caso de estudio 1 & Caso de estudio 2 & Caso de estudio 3 \\
\hline $\begin{array}{l}\text { Nombre del ámbito } \\
\text { de estudio }\end{array}$ & Horta de Lleida & $\begin{array}{l}\text { Hortes de } \\
\text { Santa Eugènia }\end{array}$ & Horts de Sant Jaume \\
\hline $\begin{array}{l}\text { Planeamiento urbano } \\
\text { incorporado en el } \\
\text { análisis. }\end{array}$ & $\begin{array}{l}\text { Plan General de } \\
\text { Ordenación Urbana } \\
\text { de Lleida (1952-1958). } \\
\text { Plan General Municipal } \\
\text { de Ordenación Urbana } \\
\text { de Lleida (1979-1995). } \\
\text { Plan de Espacios } \\
\text { Libres de Lleida (1994)*. } \\
\text { Plan General Municipal } \\
\text { de Ordenación Urbana } \\
\text { y Territorial de Lleida } \\
\text { (1995-2015). } \\
\text { Versión inicial del Plan } \\
\text { de Ordenación } \\
\text { Urbanística Municipal } \\
\text { de Lleida (2015-2030). }\end{array}$ & $\begin{array}{l}\text { Plan General de } \\
\text { Ordenación de la } \\
\text { Inmortal Ciudad de } \\
\text { Gerona y su zona de } \\
\text { influencia (1955). } \\
\text { Revisión del Plan } \\
\text { General de Ordenación } \\
\text { de Gerona y su zona } \\
\text { de influencia (1966). } \\
\text { Plan General de } \\
\text { Ordenación Urbana } \\
\text { de Girona y su zona } \\
\text { de influencia (1971). } \\
\text { Plan General Municipal } \\
\text { de Ordenación Urbana } \\
\text { (1987). } \\
\text { Revisión del Plan } \\
\text { General de Ordenación } \\
\text { Urbana de Girona (2002) } \\
\text { y Texto refundido de la } \\
\text { normativa (2006). } \\
\text { Plan especial de las } \\
\text { Huertas de Santa } \\
\text { Eugènia (2005)*. }\end{array}$ & $\begin{array}{l}\text { Plan d'Urbanisme } \\
\text { Directeur de Perpignan } \\
\text { (1962). } \\
\text { Plan d'Occupation } \\
\text { des Sols de Perpignan } \\
\text { (1982). } \\
\text { Plan d'Occupation } \\
\text { des Sols de Perpignan } \\
\text { revisado en 1998. } \\
\text { Plan Local d'Urbanisme } \\
\text { de Perpignan (2007). } \\
\text { Plan Local d'Urbanisme } \\
\text { de Perpignan revisado } \\
\text { en 2016. } \\
\text { Schéma de cohérence } \\
\text { territoriale de la Plaine } \\
\text { du Roussillon (2013). }\end{array}$ \\
\hline
\end{tabular}

Fuente: elaboración propia.

\section{Caracterización general de los ámbitos de estudio}

Los tres espacios analizados constituyen realidades distintas que, no obstante, comparten una misma funcionalidad económica: su aprovechamiento como zonas de producción hortícola para el consumo (en clave local, nacional o internacional, como se refleja en la tabla 2). De la misma forma, los tres espacios de referencia mantienen una relación directa con un curso fluvial y se sitúan en sus inmediaciones, de manera que, en mayor o menor medida, podemos vislumbrar ciertas dinámicas complementarias en su transformación reciente. Se trata, pues, de tres casos que podemos situar en la llamada interfaz campo-ciudad o urbano-rural (Cruz y Silva, 2016; Feito, 2018), pero también en el contexto geográfico propio de la interfaz ciudad-río o urbano-fluvial (Pellicer y Ollero, 2004; Ribas, 2007; Mulero, 2016; Santasusagna y Tort, 2019), básicas para comprender los procesos urbanizadores modernos. 
Tabla 2. Relación de las características básicas de cada ámbito de estudio

\begin{tabular}{|c|c|c|c|}
\hline Concepto & Caso de estudio 1 & Caso de estudio 2 & Caso de estudio 3 \\
\hline Ámbitos de estudio & Horta de Lleida & Hortes de Santa Eugènia & Horts de Sant Jaume \\
\hline Ubicación & $\begin{array}{l}\text { Área urbana y periurbana } \\
\text { de la ciudad de Lleida } \\
\text { (con un área de influencia } \\
\text { de alrededor de } 5 \text { kilóme- } \\
\text { tros a la redonda). }\end{array}$ & $\begin{array}{l}\text { Área periurbana de la } \\
\text { ciudad de Girona, en } \\
\text { el límite noroeste de su } \\
\text { término municipal. }\end{array}$ & $\begin{array}{l}\text { Área agrícola ubicada a la } \\
\text { puerta oriental del centro } \\
\text { de Perpinyà en la margen } \\
\text { derecha del río Tet. }\end{array}$ \\
\hline
\end{tabular}

Extensión

Aunque su extensión supera el término municipal de Lleida, podemos indicar dos datos de referencia:

a) Las parcelas hortícolas circunscritas al término municipal de Lleida, con una extensión aproximada de 19.000 hectáreas.

b) La huerta situada al margen izquierdo del río Segre en su tramo urbano, que presenta en la actualidad una superficie aproximada de 1.830 hectáreas.
Su extensión es comparti- Todo el perímetro de los da, aunque de forma desi- Horts de Sant Jaume se gual, entre los términos encuentra en el término municipales de Girona y municipal de Perpinyà. de Salt, y bajo distintos Presenta una superficie topónimos (Hortes de total de 310 hectáreas. Santa Eugènia en el caso de Girona y Hortes de Salt para el segundo caso). Para nuestra investigación nos fijamos en la porción con más entidad, la localizada en el término municipal de Girona, que presenta una superficie de 42 hectáreas.
Tipo de explotación Agricultura y ganadería agrícola intensivas, con especialización global en la fruta dulce.
Huertas sociales y comu- Horticultura de mercado nitarias, con algunas (en invernaderos o en iniciativas de producción campo abierto) y algunos ecológica. Los principales huertos familiares. cultivos son hortalizas y verduras, aunque también es posible encontrar ocras, cacahuetes, coriandro y menta.

\section{Lucrativo y, en segundo Productivo (hortícola)} término, productivo. $\quad \mathrm{y}$, en segundo término, residencial.

\author{
Productivo (hortícola) \\ $\mathrm{y}$, en segundo término, \\ residencial (organizado \\ históricamente en parti- \\ das).
}

\begin{tabular}{lll}
\hline Escala comercial $\quad$ Nacional e internacional. & Familiar y local. & $\begin{array}{l}\text { Ventas directas locales } \\
\text { para algunos operadores, } \\
\end{array}$ \\
& & nacionales e internaciona- \\
& les para otros.
\end{tabular}

Principales problemáticas observadas

$\begin{array}{lll}\text { Abandono de la actividad } & \text { Estructura de la propiedad } & \text { Dificultades para mante- } \\ \text { agraria, urbanización dis- } & \text { compleja y subparcela- } & \text { ner la actividad agrícola } \\ \text { persa, presión inmobiliaria ción, degradación y mar- } & \text { cuando los agricultores se } \\ \text { y éxodo rural. } & \text { ginalización del barrio de } & \text { jubilan, presión inmobilia- } \\ & \text { Santa Eugènia. } & \text { ria mediante la transforma- } \\ & \text { ción de edificios agrícolas } \\ & \text { en viviendas. }\end{array}$

Fuente: elaboración propia. 


\subsection{La Horta de Lleida ${ }^{2}$ y el río Segre}

La huerta, la Horta por antonomasia, es sin duda uno de los elementos característicos de Lleida y su región. La ciudad ha aprovechado los recursos del río Segre y la llanura de sus márgenes para conformar un paisaje fluvial de grandes zonas de regadío mediante la construcción de un sistema complejo de canales que han aportado una gran riqueza a su población. Si bien el clima de la región es seco y árido, la huerta forma parte imprescindible del paisaje ilerdense, sin la cual no puede comprenderse la evolución de su morfología urbana ${ }^{3}$.

A efectos de este artículo consideramos como Horta de Lleida una vasta extensión de parcelas agrarias situadas en el área urbana y periurbana de la ciudad de referencia — en un radio de, aproximadamente, cinco kilómetros- - y que suponen una ocupación aproximada de 19.000 hectáreas (Ajuntament de Lleida, 2017) repartidas de un modo bastante heterogéneo a medida que nos alejamos del centro urbano.

Cabe comentar que la Horta de Lleida, más que un espacio agrícola circunscrito a un área reducida y concreta, puede calificarse como un continuo rural-urbano que se superpone a las divisiones municipales existentes y que constituye la base de la actividad agroganadera y agroindustrial del extenso entorno de Lleida. En todo caso, para nuestra investigación es importante hacer hincapié, específicamente, en las zonas hortícolas más próximas al río Segre (mapa 1), pues son las que han sufrido los efectos de la transformación urbana reciente con mayor intensidad.

En las últimas décadas, la Horta de Lleida, que ya había registrado una mutación importante a finales de los años cincuenta con la modernización de la técnica agrícola y la especialización global en la fruta (Feixa, 1993), sufre de nuevo un cambio urbanístico sin precedentes (Aldomà, 2008, 2013). Un cambio ligado al abandono de la actividad agraria, una urbanización dispersa generalizada y la puesta en marcha de varias operaciones de nuevo suelo industrial, así como un éxodo rural que ha comportado, a lo largo del tiempo, un envejecimiento importante de la población residente (Mayoral, 1993).

2. Hablamos de horta en el sentido que este concepto tiene en el léxico catalán tradicional: «Terreno regable, generalmente de gran extensión, en el cual se cultivan preferentemente verduras, legumbres y árboles frutales» (Diccionari català-valencià-balear, 1980, VI, p. 555). El término equivalente en castellano es vega o huerta. En Cataluña, Horta de Lleida es quizá el mejor ejemplo de su materialización como topónimo.

3. Joan Ganau cita a un viajero, Antonio Ponz, que describe la Horta de Lleida de finales del siglo Xvi de la siguiente forma: «Quisiera yo hacer un alto por un instante y comparar la ingeniosa industria de los pasados ilerdenses en buscar su utilidad violentando a los ríos para conseguirla, y horadando peñascos por donde corriesen las aguas con la flojedad de otros mil pueblos de España que, pudiéndose aprovechar de los suyos con menor trabajo que les costó a los de Lérida, dejan pasar a los ríos y arroyos por sus términos, sin sacar de ellos ningún provecho» (Ganau, 1992: 25). 
Figura 2. La extensa Horta de Lleida es el resultado de un sistema complejo de canales históricos y modernos. En la imagen se observa un tramo del llamado canal de Pinyana, situado al norte del término municipal

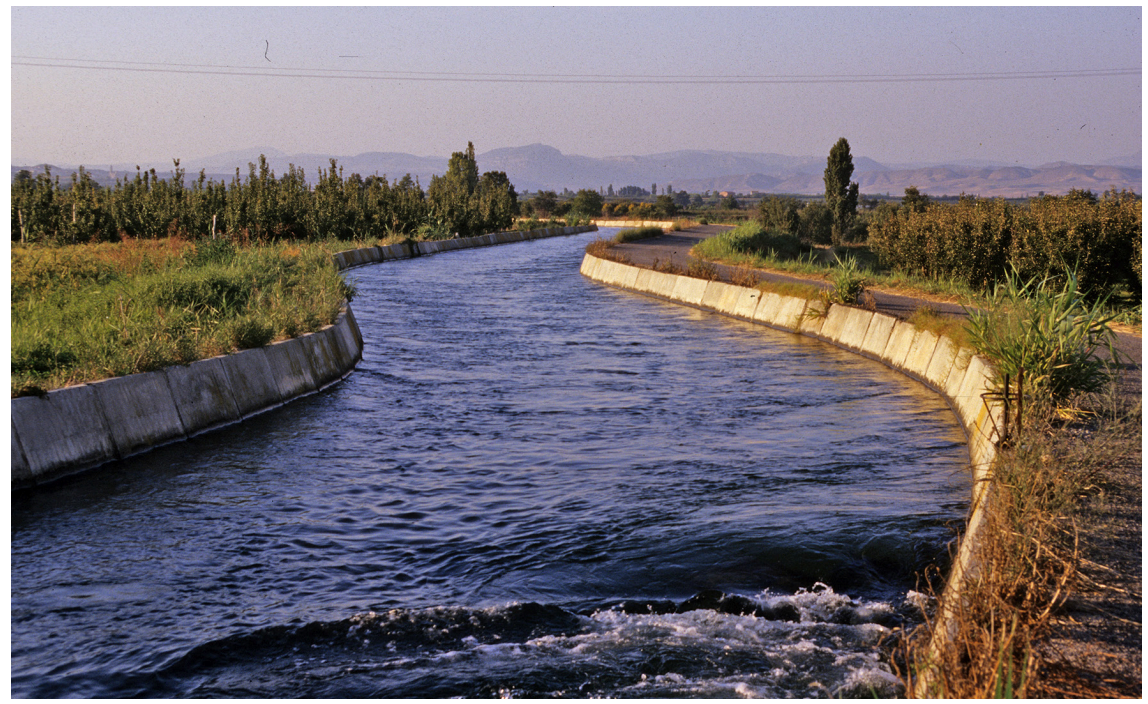

Fuente: archivo propio de los autores.

Mapa 1. Relación de los principales elementos histórico-geográficos que conforman el paisaje del río Segre y su huerta en Lleida

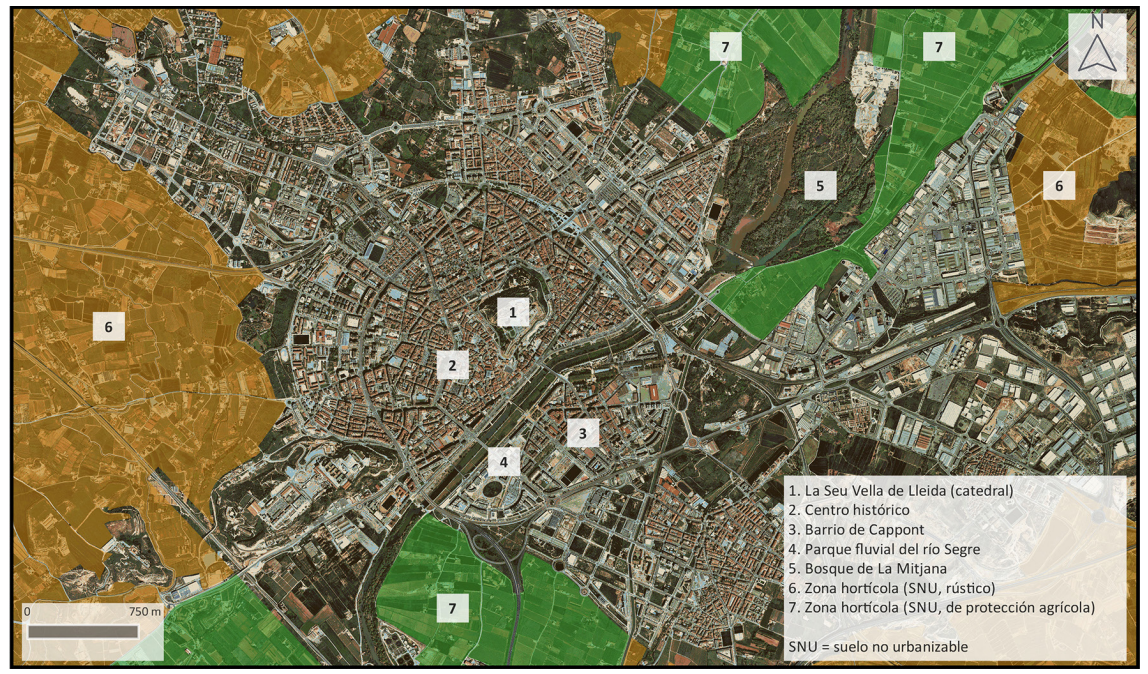

Fuente: elaboración propia a partir de ortofotografía (ICGC, 2018) y clasificación del suelo del Mapa urbanístico de Cataluña (MUC). 


\subsection{Las Hortes de Santa Eugènia ${ }^{4}$ (Girona)}

Las Hortes de Santa Eugènia (mapa 2), pequeño ámbito agrícola situado al noroeste del término municipal de Girona, toman este nombre por su vinculación al antiguo municipio de Santa Eugènia de Ter, anexionado a la capital provincial en 1963 y hoy en día distrito urbano (Ribas, 2001). Con una superficie aproximada de 42 hectáreas (Ajuntament de Girona, 2005), este conjunto de huertos forma parte de la superficie regada por la acequia Monar ${ }^{5}$, una estructura hidráulica de origen medieval de 6 quilómetros de longitud que toma el agua de la presa de la Pilastra —en el término municipal de Bescanó-, cruza ciudades como Salt y llega hasta el Onyar, afluente del río Ter, en la parte norte de la trama urbana de Girona. Se trata de una obra que, aunque documentada ya en el siglo XI, alcanzó su máximo apogeo a finales del siglo XIX con su remodelación para fines industriales, hidroeléctricos y agrícolas (Sureda, 2002), y con el establecimiento a su vera de algunas de las empresas textiles más importantes del entorno de la ciudad. Este es el principal motivo de la existencia de varios edificios fabriles repartidos por la zona hortícola de Salt — como la fábrica Gasol_-, el barrio de Santa Eugènia —con la antigua fábrica de hilados Marfa, hoy reconvertida en equipamientoy el barrio gerundense del Mercadal —en este caso, con la fábrica Grober como principal ejemplo.

El declive funcional de la industria textil ha dado paso, a lo largo del último medio siglo, a una reconversión en nuevos equipamientos y en proyectos de rehabilitación urbana, como los realizados en Can Po Vell. Este cambio de función también ha tenido su reflejo en el uso agrícola: el progresivo abandono de las tierras ha dado lugar, a lo largo de las últimas décadas, a la creación de huertas sociales y comunitarias gestionadas por el Ayuntamiento de Girona y cedidas a los ciudadanos del barrio de Santa Eugènia para su cultivo y mantenimiento. Así pues, el perfil del «hortelano» ha cambiado completamente en pocos años, y ha sido el propio Ayuntamiento el que ha intentado recuperar el patrimonio agrícola (huertas y edificios asociados) a través, precisamente, del planeamiento urbano. Desarrollaremos esta cuestión en particular en el epígrafe 4.2.

4. No tenemos constancia del nombre Hortes de Santa Eugènia como topónimo tradicional del lugar. En un sentido semántico estricto, debería hablarse de Horts de Santa Eugènia, sin embargo, en la medida que el planeamiento municipal de las dos últimas décadas utiliza sistemáticamente aquella denominación, hemos preferido adoptarla también para nuestro artículo.

5. El Diccionari català-valencià-balear (1980, VII, p. 532) señala que el término monar proviene del latín molināre y hace referencia a 'molino de agua'. Es, en lengua castellana, un sinónimo de aceña, si bien este vocablo alude, específicamente, a un molino harinero de agua situado en el cauce de un río. 
Figura 3. Un hortelano pasea junto a los nuevos espacios comunitarios gestionados por el Ayuntamiento de Girona

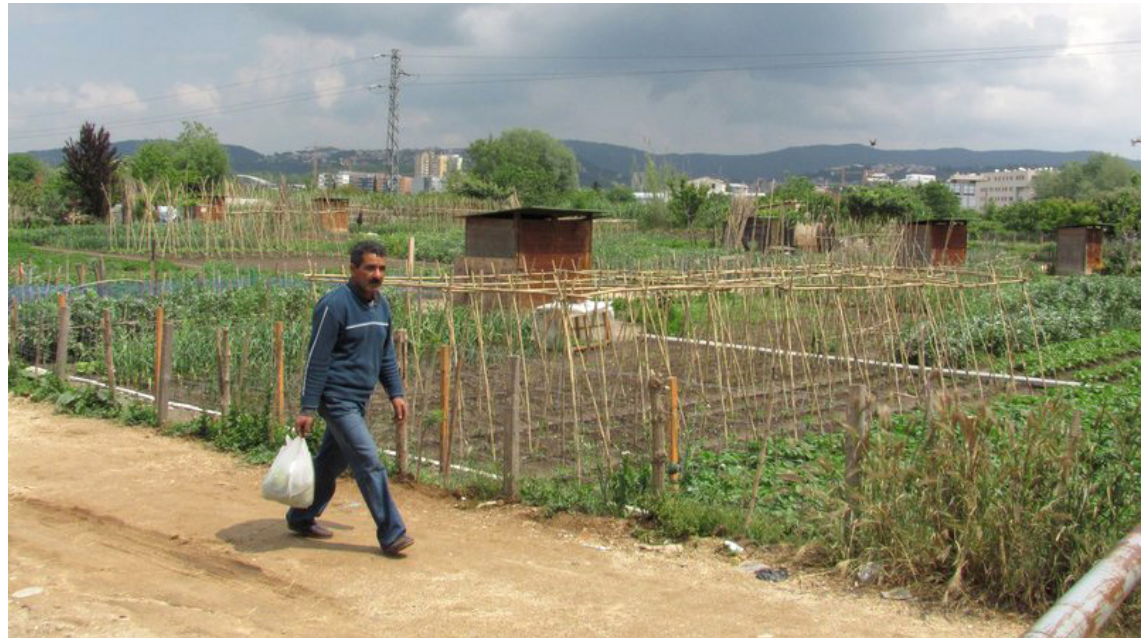

Fuente: El Punt Avui.

Mapa 2. Localización de las Hortes de Santa Eugènia en el contexto urbano de los límites municipales entre Girona y Salt

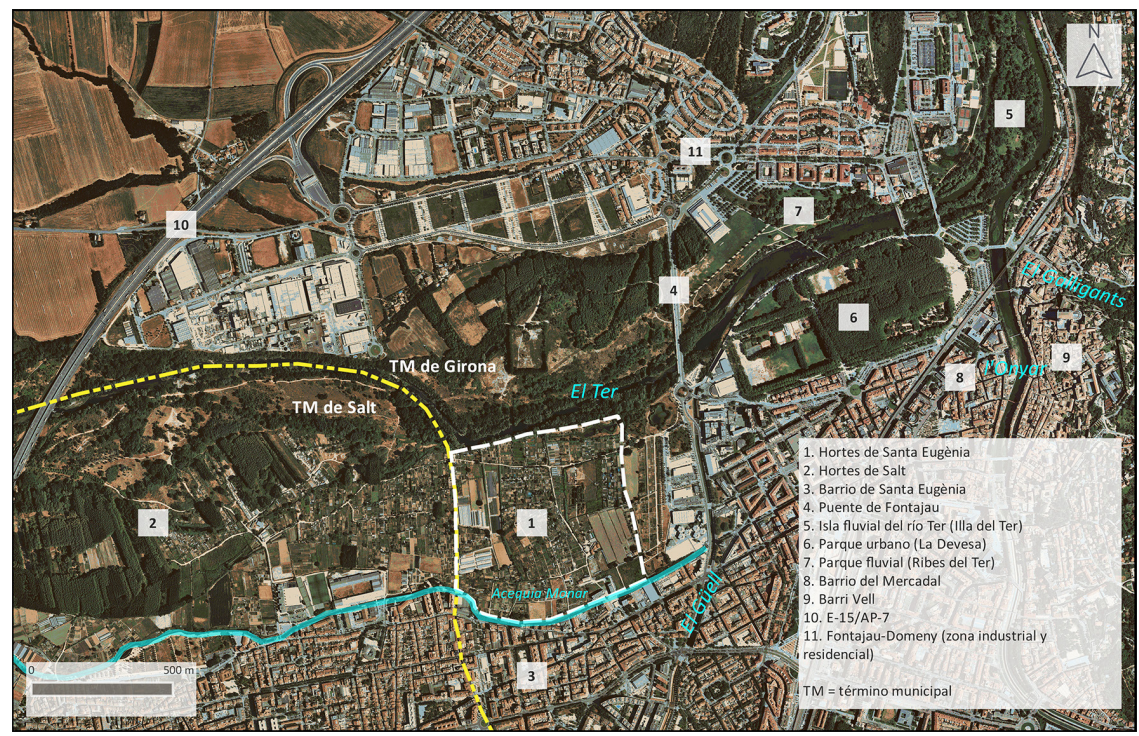

Fuente: elaboración propia a partir de ortofotografía (ICGC, 2018) y clasificación del suelo del Mapa urbanístico de Cataluña (MUC). 


\subsection{Els Horts de Sant Jaume junto al río Tet, en Perpinyà}

Los Horts de Sant Jaume constituyen un área hortícola de 310 hectáreas ubicada al este del centro de Perpinyà (mapa 3). Limitan al norte con el río Tet, al sur con la autopista D617, al este con una colina y al oeste con el área urbana de Perpinyà y un eje vial (mapa 4). Estos huertos conforman el corazón histórico del área agrícolamente productiva del entorno más próximo a Perpinyà. Un breve análisis de la cartografía de la ciudad del siglo XIX (como los mapas de 1850 y de 1898, del IGN) refleja una especialización agrícola ya bien esta-

Mapa 3. Ortofotografía general del término municipal de Perpinyà

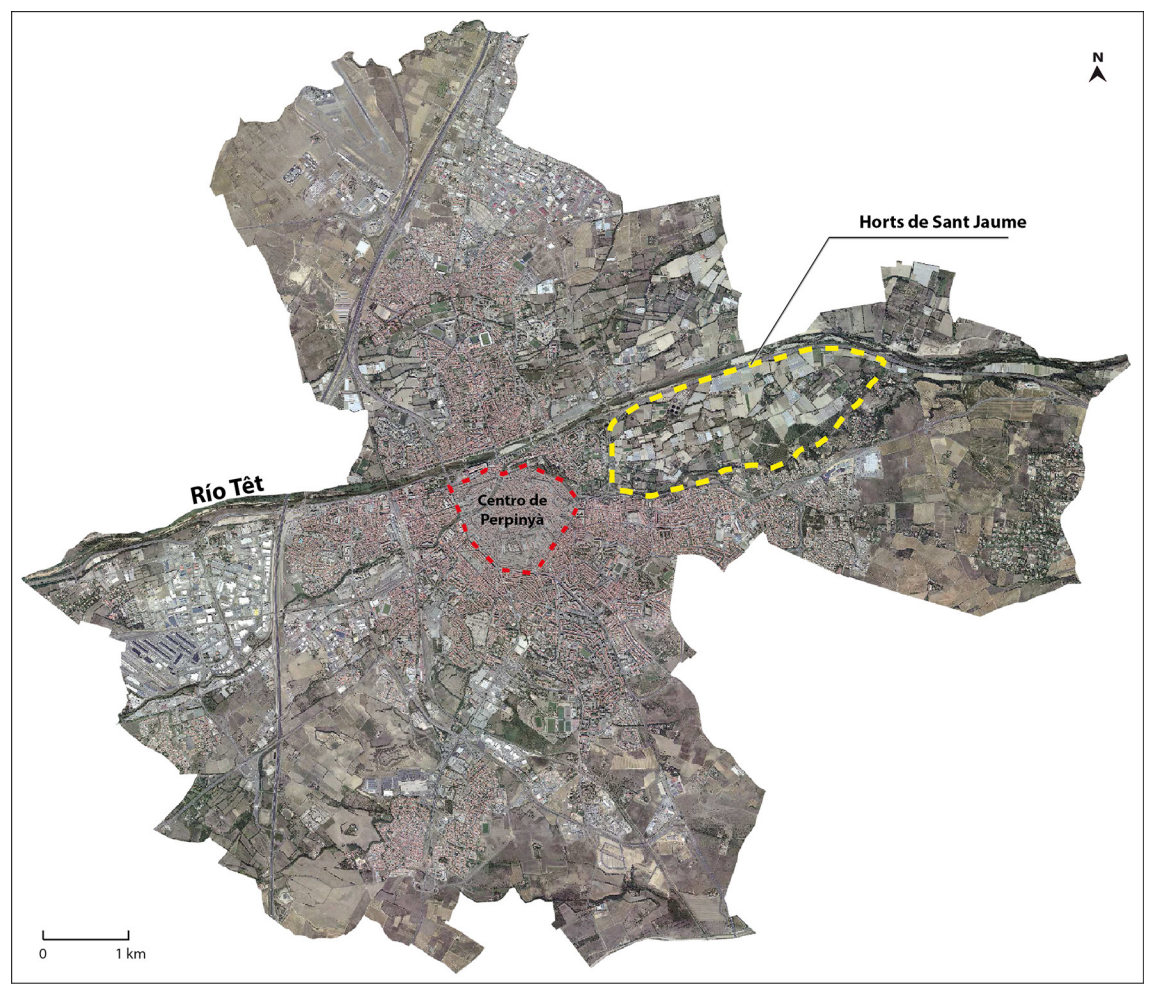

Fuente: elaboración propia a partir de información cartográfica disponible en Géoportail.

6. Adoptamos en este caso el topónimo popular local, Horts de Sant Jaume, como referencia, aunque la denominación prevalente, tanto en el planeamiento como en la cartografía francesa que hemos utilizado, sea Jardins Saint-Jacques. Queremos hacer notar que en las últimas décadas ha habido un esfuerzo importante por parte de la Administración francesa (y en especial el IGN) en pro de la normalización, en la cartografía y en la señalización pública de los territorios bilingües — como es, en nuestro caso, el Rosselló-, de la denominada toponimia menor. Sin embargo, la materialización de este proceso es lenta y entraña notables dificultades, por lo que cabe pensar que se irá completando a largo plazo. 
Mapa 4. Delimitación de los Horts de Sant Jaume. Se pueden observar, en color rosa, las parcelas dedicadas a la producción intensiva de hortalizas y, en color rojo, las que producen fruta

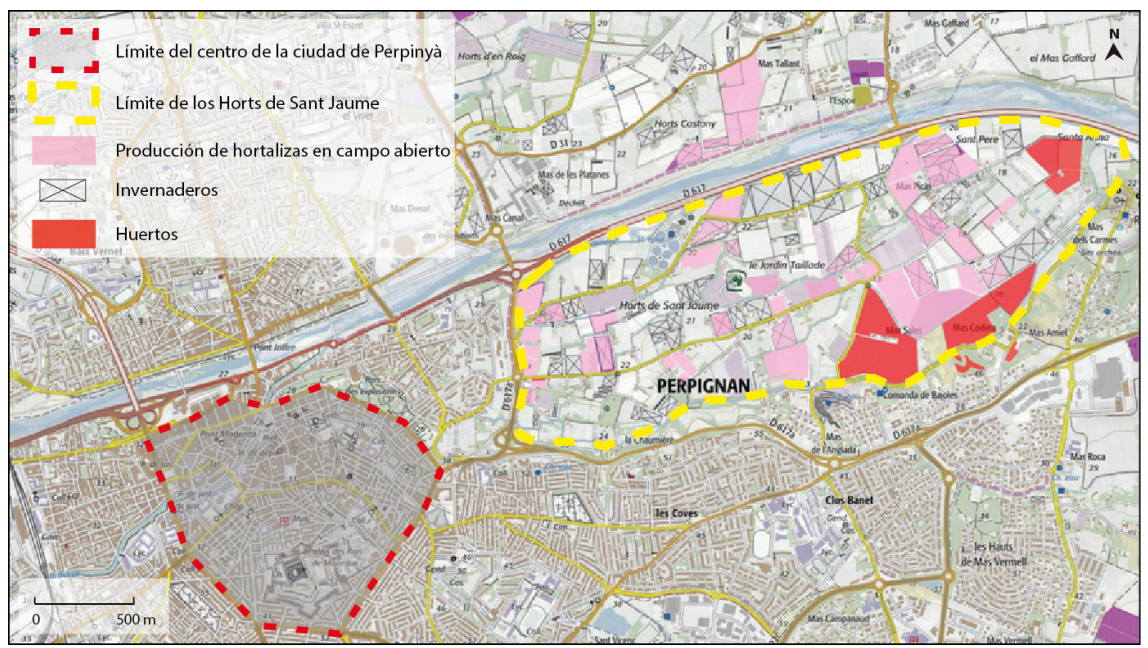

Fuente: elaboración propia a partir de información cartográfica disponible en Géoportail.

Figura 4. Visión panorámica de los Horts de Sant Jaume en Perpinyà en 2019

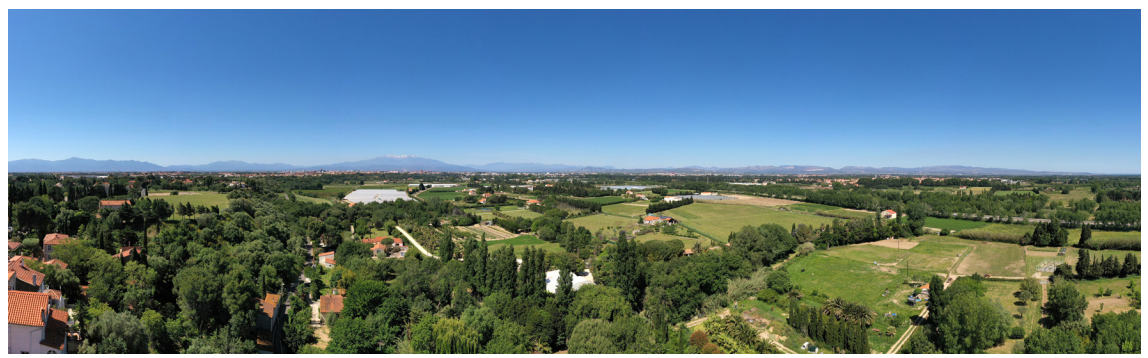

Fuente: fotografía realizada por Yingzhe Li, estudiante de Geografía en la Université de Perpignan Via Domitia (UPVD).

blecida en aquel tiempo, que se ha beneficiado del dinamismo del mercado de interés nacional de Perpinyà hasta la actualidad.

Nuestra área de estudio coincide con una zona de tierras bajas formada por depósitos aluviales del Tet. Está especializada en la producción intensiva de hortalizas en campos abiertos e invernaderos (lechugas, pepinos, tomates, etc., que se muestran de color rosa en el mapa 4) y algunos huertos que permiten la producción de frutos (en color rojo en el mapa 4). Algunas explotaciones se han orientado hacia mercados especializados y comercializan sus productos en tiendas y restaurantes gourmet en toda Francia (por ejemplo, con la producción de vegetales de pequeño tamaño). 


\section{Resultados}

En este apartado abordamos el análisis material del planeamiento urbano aprobado por los respectivos consistorios municipales a lo largo de los últimos setenta años, con el objetivo de interpretar los cambios y las implicaciones en el paisaje que se han derivado de su progresiva implementación. Tal como hemos señalado antes, hemos tenido en cuenta no solo la planificación municipal de ámbito general, sino también la planificación especial con incidencia en el paisaje agrario de referencia.

\subsection{La transformación urbana del paisaje hortícola del Segre en Lleida}

Desde los años 1950 hasta la actualidad, el Ayuntamiento de Lleida ha aprobado tres planes urbanísticos generales y, coincidiendo con la realización del presente estudio, se ha procedido a la aprobación inicial de un último plan municipal —en abril de 2018-. Todos ellos, sin excepción, asumen el espacio agrícola como referente fundamental, sea para el desarrollo urbano, sea para su protección. A continuación sintetizamos la información presente en cada uno de los planes para comprender el escenario actual, objeto directo de nuestro estudio. En todo caso es importante subrayar que, por lo que respecta a Lleida, es necesario plantear el análisis en un doble sentido: de entrada, en relación con la superficie hortícola del conjunto del término municipal; en un segundo nivel, en relación con el espacio agrícola de la margen izquierda del Segre y con un vínculo directo con el río.

En el contexto descrito, el primer plan aprobado es el llamado Plan General de Ordenación Urbana de 1952-1958 (PGOU) ${ }^{7}$. Un plan que fija ocho criterios básicos de actuación con un horizonte para el año 2000: "población", «industria», "agricultura», "ferrocarriles», "carreteras», "casco antiguo y ensanches», "valores estéticos» y «nuevos ensanches». Se trata de un instrumento muy comprometido con la contención del espacio urbano de Lleida y, por lo tanto, preocupado por un desarrollo excesivo y descontrolado. En este sentido, es marcadamente conservacionista con el espacio agrícola: «La limitación de la ciudad por razones económicas y de funcionamiento, y la necesidad de conservar zonas de reserva agrícola, marcan el criterio de limitar la expansión

7. La literatura científica sobre el planeamiento urbano de Lleida (Llop-Torné, 1995) hace referencia a sus planes históricos con una horquilla de años que se ajusta a diferentes circunstancias. Tal y como se puede constatar, el Plan General de Ordenación Urbana de 1952-1958 toma este nombre porque en el primer año, 1952, se presentó una primera redacción, que no fue aprobada definitivamente hasta 1958. Por otra parte, el resto de planes estudiados en este epígrafe (Plan General Municipal de Ordenación Urbana de 1979-1995 y Plan General de Ordenación Urbana y Territorial de 1995-2015) reciben estos nombres por el horizonte temporal que adoptan, normativamente, cada uno de ellos. Aunque en el resto de casos de estudio no operamos de esta misma forma, en el caso de Lleida consideramos que es importante respetar esta nomenclatura a fin de adecuarnos a las referencias académicas existentes.

8. El Plan adopta, pues, el año 2000 como horizonte temporal, y realiza una previsión demográfica para esta fecha de 110.580 habitantes, cifra que calcula a partir de las tasas de crecimiento medio de la ciudad y que se ajusta bastante a la que termina dándose (112.194 habitantes el año 2000, según fuentes del IDESCAT). 
de la ciudad [...] y de proteger el campo contra la edificación concentrada y desordenada [...]» (Ajuntament de Lleida, 1958). A tal efecto, el Plan no propone una expansión urbana más allá de la margen derecha (donde, históricamente, se había establecido la ciudad de Lleida), de manera que la margen izquierda solamente es objeto de pequeñas intervenciones relacionadas con la prolongación del espacio verde existente (como es el caso de los jardines históricos de los Campos Elíseos) y con una renovación y nueva construcción de infraestructuras de comunicación de ambas márgenes fluviales.

El cambio paisajístico más importante para el espacio agrario vinculado con el tramo urbano del río Segre - y para la ciudad de Lleida en generaltiene su razón de ser en los planes de las primeras décadas de la democracia: el Plan General Municipal de Ordenación Urbana (1979-1995) y el subsiguiente Plan General Municipal de Ordenación Urbana y Territorial de Lleida (1995-2015). Las márgenes fluviales recuperan entonces un protagonismo que no tenían en la anterior planificación: son asumidas como ámbito de acogida de determinados desarrollos urbanos, y también aparecen como destinatarias de una extensa franja de nueva zona verde. El primer plan, a fin de cumplir con la normativa vigente — la Ley 19/1975, de 2 de mayo, de reforma de la Ley sobre régimen del suelo y ordenación urbana-y llegar a la cifra de $5 \mathrm{~m}^{2}$ de espacio verde por habitante, se fija en las riberas del río Segre para albergar la creación de un nuevo parque fluvial ${ }^{10}$ que, a través de la planificación especial y con la aprobación del plan posterior, se concibe con capacidad de conectar con el resto de espacios verdes urbanos y periurbanos ${ }^{11}$. El proyecto, que implica la canalización del río tras la inundación catastrófica de 1982 12 , también promueve la colonización urbana de la margen izquierda. El llamado barrio de Cappont ${ }^{13}$, hasta ese momento con un cierto equilibrio entre espacio urbano y

9. Con el objetivo de homogeneizar la bibliografía correspondiente al planeamiento urbano, se ha adoptado el nombre oficial actual de los consistorios (Ajuntament de Lleida, Ajuntament de Girona y Mairie de Perpignan). No obstante, indicamos en las referencias bibliográficas su nombre histórico (siempre que proceda).

10. Se trata, específicamente, de un parque lineal de aproximadamente 2,5 kilómetros y con una inversión de 24 millones de euros sufragada por el consistorio, la Generalitat de Catalunya y el Ministerio de Fomento del Gobierno de España (Llop-Torné et al., 2002).

11. El Plan de Espacios Libres de Lleida (1994) toma como una de sus prioridades la gestión de los espacios periurbanos de contacto entre la ciudad y la huerta, donde «el río tiene que ser una pieza clave en este intercambio», con tal de "superar la concepción de tramo fluvial urbano y pasar a ser concebido como un elemento del territorio que atraviesa la ciudad y vuelve a introducirse en el territorio» (Ajuntament de Lleida, 1994: 62).

12. La inundación de 1982 marca un antes y un después en la historia urbana de Lleida, y repercute, lógicamente, en el orden prioritario de medidas e intervenciones a realizar en el marco del Plan General Municipal de Ordenación Urbana de 1979-1995. Es por este motivo que la mayor parte de sus provisiones se orientan a la mejora de infraestructuras y de servicios urbanos, así como a la urbanización de nuevos espacios.

13. El Diccionari català-valencià-balear recoge el término cappont (1980, II, p. 983) con el significado de 'extremo de un puente'. Podemos interpretar, pues, que el barrio de Cappont en Lleida es aquel que se sitúa 'más allá del puente' (esto es: el Pont Vell, la conexión más antigua de la ciudad). 
hortícola ${ }^{14}$, es concebido y desarrollado como nueva zona de servicios gracias a su vertebración con nuevas calles y avenidas y con la construcción de edificios singulares - como el nuevo campus universitario, con la intención de consolidar el perfil en este sentido que Lleida ha ido adquiriendo (Bellet, 2011) — u otros espacios de carácter lúdico y comercial. Así pues, la función hortícola de la margen izquierda queda relegada a un segundo lugar, mientras se potencian los usos residenciales, sociales y lúdicos.

No obstante, los retos urbanos de Lleida no terminan con esta planificación. Recientemente, el Ayuntamiento de la ciudad ha emprendido las tareas de elaboración del anteproyecto de Plan de Ordenación Urbanística Municipal (POUM), que ya ha superado la fase de aprobación inicial. Se trata de un documento que, a grandes rasgos, propone una serie de objetivos de gran calado relacionados con el sistema de espacios libres: la creación de una ronda verde circular y perimetral en la interfaz ciudad-huerta - capaz de acoger rutas, caminos y senderos que conecten los barrios periféricos- y creación de una zona específica de entorno agrícola destinada a la potenciación de productos locales y al desarrollo de figuras de impulso económico, como los parques agrarios (medidas que también acaban concretándose, paralelamente, en el Plan de Usos de la Huerta de Lleida aprobado en 2017).

En cualquier caso, una consideración sintética de la planificación urbana de Lleida a través del tiempo nos hace evidente que, aunque el espacio hortícola de la ciudad se contempla a priori como un valor añadido, otra cosa ha sucedido en el momento de concretar esta determinación en los instrumentos de planificación. Advertimos así, en numerosas ocasiones, que no se ha dudado a la hora de permitir la conversión de la huerta (sobre todo en la franja más próxima al río) en espacio urbanizado. Sobre todo a raíz de la gran inundación de la década de 1980 y con motivo de la «necesidad», entonces planteada, de canalizar el río. Una circunstancia que se sumó a la voluntad, expresada de un modo recurrente, de expandir la ciudad al otro lado del Segre.

\subsection{La nueva funcionalidad de la zona hortícola de Santa Eugènia en Girona}

Aunque el municipio de Santa Eugènia de Ter, como ya hemos mencionado, es anexionado a Girona en 1963, ya en el primer plan general aprobado por el consistorio de la ciudad (en 1955) se hacía patente una voluntad política de favorecer la continuidad urbana entre Girona y los municipios circundantes; o, dicho de otro modo, de expandir la capital más allá de sus límites: «Hoy en día no existe solución de continuidad entre la capital y Salt, y Santa Eugènia, formando un mismo núcleo y con problemas comunes» (Ajuntament de

14. Equilibrado, pero degradado. El barrio de Cappont acogió, durante los fenómenos migratorios internos de España en los años 1960 y 1970, una cantidad importante de nueva población (Bellet, 1994). No obstante, la gestión urbana de este barrio fue muy deficiente, tal y como ocurrió en otras ciudades catalanas, y estos espacios no disponían de los servicios mínimos para su habitabilidad. 
Mapa 5. El Plan de Espacios Libres de Lleida y la ordenación de los espacios verdes urbanos y periurbanos. Se puede observar que el área verde cubre los espacios fluviales, con el objetivo de establecer una «transición amable» entre ciudad y huerta

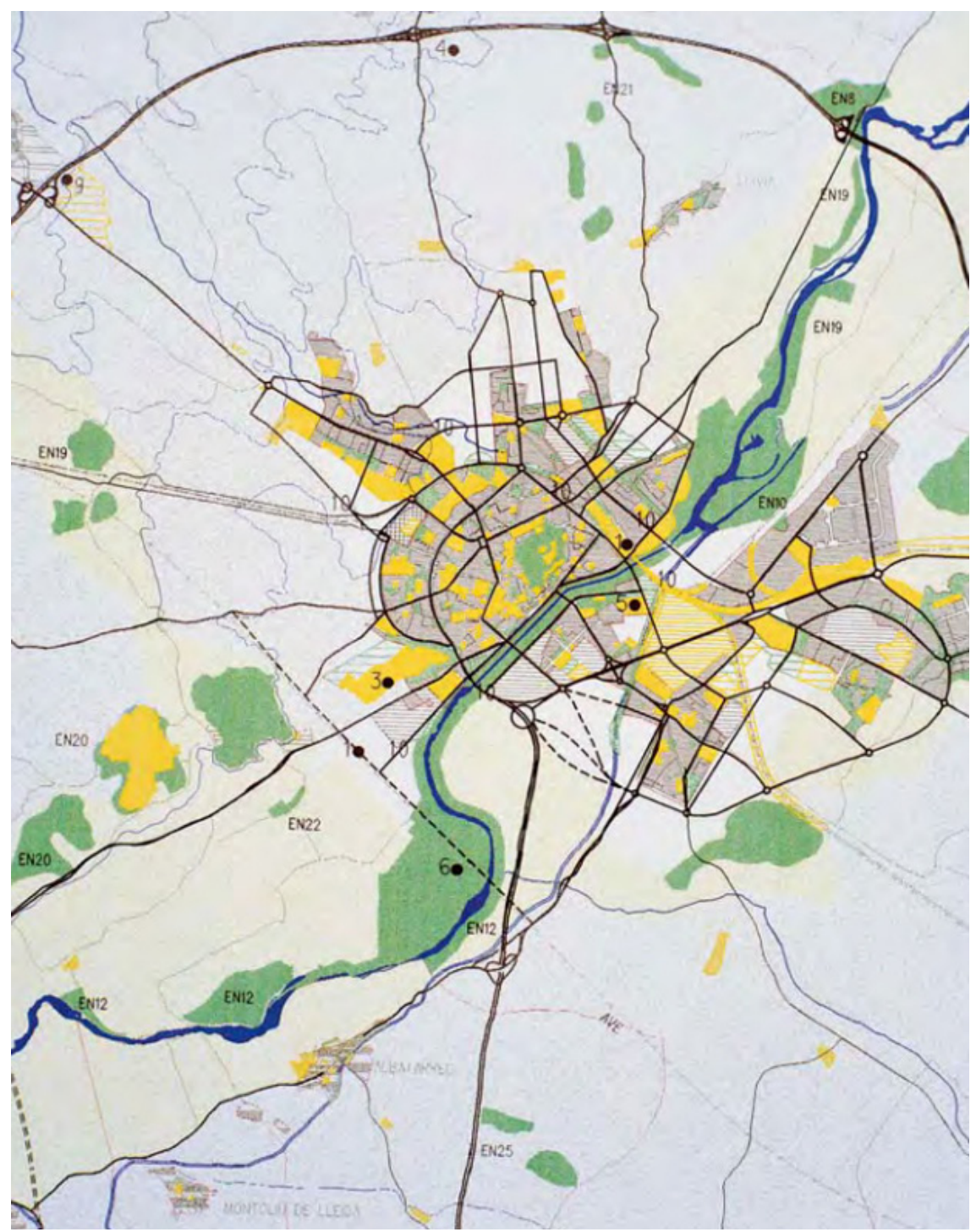

Fuente: Llop-Torné et al. (2002).

Girona, 1955: 14). Santa Eugènia, un espacio de vocación originariamente rural (constituido en buena medida por huertas y pequeñas edificaciones para los hortelanos), se va convirtiendo progresivamente en un nuevo barrio gerun- 
dense. Y aunque el perfil agrario de dicho sector tiende a ser respetado en su mayor parte mediante su consideración como zona de reserva de suelo agrícola, en la planificación inmediatamente posterior (concretamente, en la Revisión del Plan General de Ordenación de Girona y su zona de influencia, 1966), se promociona, de un modo correlativo, su conexión con Girona y Salt a través de infraestructuras de comunicación viarias.

Entre las décadas de 1960 y 1970 (y con la aprobación del Plan General de Ordenación Urbana de Girona de 1971), la zona edificada aumenta y acaba formándose un continuo urbano entre Salt, Santa Eugènia y Girona ${ }^{15}$. Este acrece, nuevamente, con el desarrollo de infraestructuras de paso del río Ter entre finales de la década de 1980 y principios de la de 1990 (en especial, con la construcción del puente de Fontajau, que conecta ambas márgenes del río entre las huertas y la zona de la Devesa). En dicho contexto encontramos un reducto de 42 hectáreas de huerta (que devendrá la base de este caso de estudio) que sobrevive de forma sorprendente a toda la planificación moderna. Pese a todo, dicho reducto, circundado por espacios estrictamente urbanos e infraestructuras de comunicación, mantendrá su carácter agrario y su calificación como zona no urbanizable desde entonces hasta la actualidad.

Ni la planificación actual (Revisión del Plan General de Ordenación Urbana de Girona de 2002 y Texto refundido de la normativa de 2006) ni la inmediatamente anterior (Plan General Municipal de Ordenación Urbana de 1987) ponen en duda la calificación de este espacio como no urbanizable, hecho que no obsta para que su degradación a lo largo de todo este periodo sea progresiva. De hecho, el Plan General de Ordenación Urbana de 2002 propone la redacción de una planificación especial para las Hortes de Santa Eugènia, con el objetivo de "proteger y recuperar el paisaje con un criterio unitario de actuaciones tanto para las infraestructuras, rehabilitaciones de elementos arquitectónicos [...] como para la recuperación de áreas de interés ecológico [...] [concibiendo] el área de las huertas como una gran pieza verde esencial dentro del mosaico de la ciudad [...]» (Ajuntament de Girona, 2002: 46) ${ }^{16}$. Y, concretamente, pone encima de la mesa la necesidad de «mantener el uso de la huerta tradicional», «mantener la red de riegos y crear una comunidad de regantes», «recuperar y conservar los elementos arquitectónicos que configuran el paisaje tradicional de las huertas» y «establecer un sistema de suelo público necesario para lograr estos objetivos» (Ajuntament de Girona, 2002: 47). Una

15. Durante la década de 1970 Girona verá aumentada su población de forma considerable con la llegada de personas del resto de España, sobre todo del sur. Buena parte de esta nueva población se concentró en Salt y el barrio de Santa Eugènia, que presentaban las más altas densidades de población del municipio. Según datos del INE, Girona pasó de tener 28.915 habitantes en 1950 a 50.338 en 1970; es decir, un aumento de casi el doble de la población existente. Este fenómeno tiene una segunda fase en la década de 1990, con la llegada de inmigración extracomunitaria. En este sentido, Santa Eugènia ha representado - y sigue representando en la actualidad - un barrio con importantes deficiencias socioeconómicas, objeto también del llamado Pla de Barris (Ley 2/2004, de 4 de junio, de mejora de barrios, áreas urbanas y villas que requieren una atención especial).

16. Traducción de los autores (del catalán al castellano). 
Mapa 6. Mapa de ordenación general de la planificación especial de las huertas del barrio de Santa Eugènia. Se pueden observar los tres escenarios principales: la zona norte o C5 (para humedales y restauración ecológica), la central o C4 (para huertas sociales y comunitarias) y la sur o C4a (para su conversión en parque agrícola)

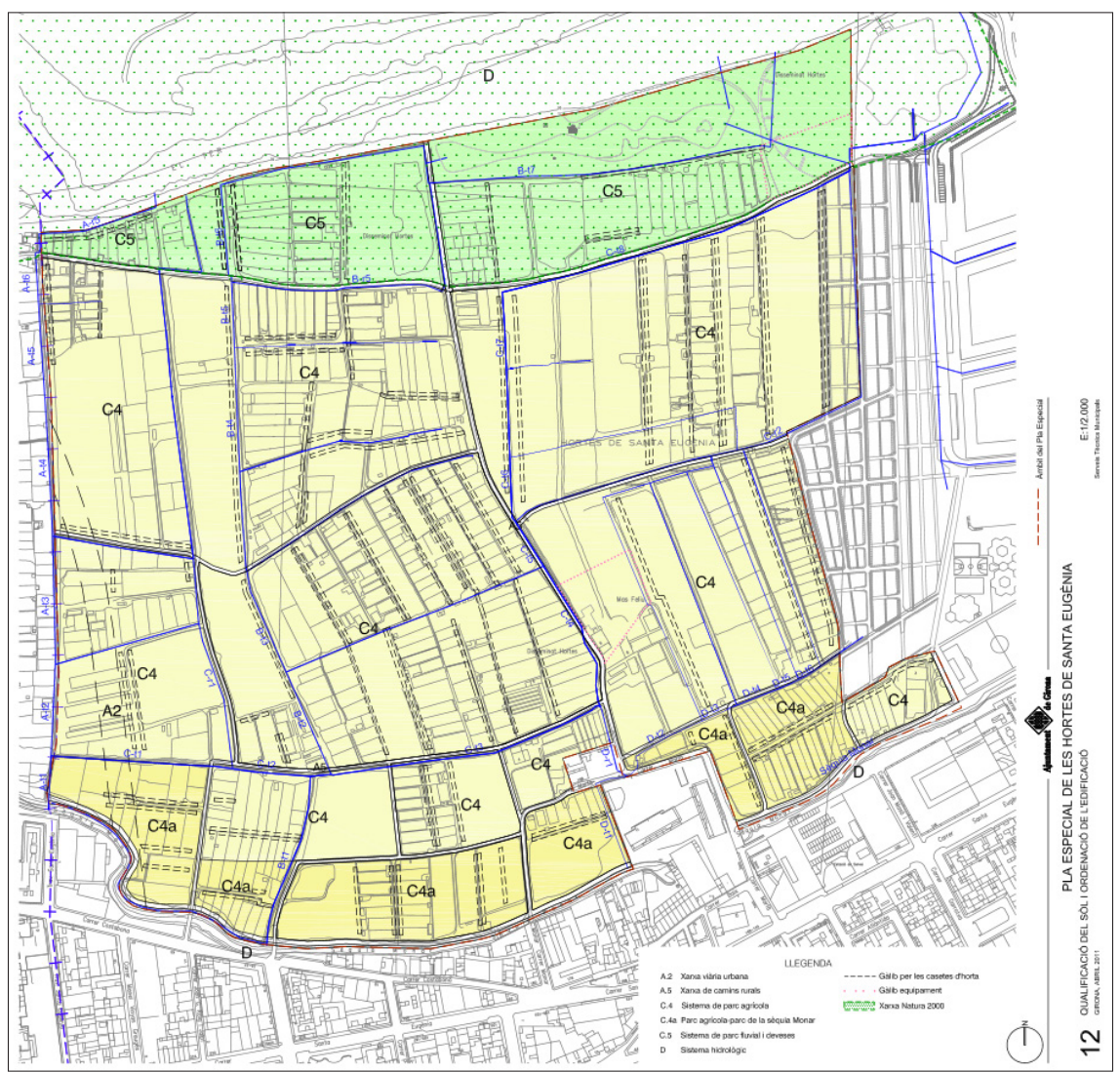

Fuente: Plan especial de las Hortes de Santa Eugènia (2005).

serie de propósitos concretos que denotan la situación degradada del espacio hortícola de Santa Eugènia en esa década y que nos habla de una problemática diferente del resto de casos de estudio: la existencia, aquí, de un paisaje protegido sobre el papel, pero progresivamente abandonado y devenido "paisaje fósil», a la espera de una operación de regeneración — que no llega hasta tres años más tarde, con la aprobación del plan especial.

En efecto, el Plan especial de las Hortes de Santa Eugènia se aprueba en 2005 y tiene el objetivo básico de ordenar el espacio hortícola en tres sectores con escenarios diferentes entre sí. Por una parte, la zona más próxima al río Ter, concebida como espacio de restauración ecológica de humedales (con una superficie total de 6,4 hectáreas); por otra, la zona central (27,88 hectáreas), 
destinada a huertas sociales y comunitarias — es decir, de titularidad pública, pero con un sistema de alquileres abierto a la ciudadanía y apuntando a la recuperación de los usos históricos hortícolas y con criterios de agricultura ecológica—, y, finalmente, la zona sur (4,8 hectáreas) — la más compleja a nivel jurídico por su subparcelación y el gran número de propietarios-, proyectada como un futuro parque agrario paralelo a la acequia Monar. En este último caso se plantea llegar a una serie de acuerdos con la propiedad y, también, expropiar las parcelas que se han ido abandonando (Rubert, 2005).

Desde la aprobación del Plan especial hasta la actualidad, los objetivos formulados a corto y medio plazo se han cumplido en su mayor parte, mientras que la conversión de la zona sur a titularidad pública ha sido una tarea mucho más difícil. De hecho, el objetivo básico de esta operación - mantener el uso tradicional de la huerta con la promoción de agricultura ecológica- no ha tenido demasiado éxito. El uso lúdico de las huertas se ha impulsado a través de la creación de itinerarios culturales y la rehabilitación de edificaciones de antiguos hortelanos, pero uno de los riesgos permanece latente: la huerta "profesional», abandonada y sustituida por una de tipo social, no ha conseguido recuperar sus usos históricos de forma plena. En la actualidad existen parcelas abandonadas, y el carácter marginal del espacio es aún una realidad. La planificación, pues, ha conseguido proteger el espacio frente a la presión urbanística, pero el escenario es mucho más complejo de lo que determina el papel.

\subsection{Perpinyà y su zona de huerta: La evolución reciente de un paisaje agrícola inserto en la periferia urbana de la ciudad}

Desde mediados del siglo xx hasta hoy, la ciudad de Perpinyà se ha dotado de cinco documentos de planificación urbana. Desde el Plan d'Urbanisme Directeur (PUD) de 1962 hasta el Plan d'Urbanisme Local de 2016. Todos estos documentos revelan una notable continuidad en su deseo de preservar la vocación agrícola de los Horts de Sant Jaume. La revisión de la zonificación establecida en estos documentos muestra que la función agrícola de esta área está reconocida y sistemáticamente protegida. En el PUD de 1962 se clasifican como "zona rural», es decir, se asignan a actividades agrícolas (y solo se permiten construcciones vinculadas a esta actividad). El subsiguiente Plan d'Occupation des Sols (POS) de 1982 (mapa 7) los clasifica como «zona $\mathrm{NC}$, una calificación que responde al área natural asignada a las explotaciones agrícolas y a las instalaciones relacionadas con la agricultura en este tipo de planes en Francia.

El POS de 1998 (mapa 8) mantiene esta clasificación (como «zona NC») simplemente introduciendo un pequeño cambio representado por la zonificación $\mathrm{NC1}$ r - una letra erre que evoca la exposición de este espacio al riesgo de inundación-. De hecho, en este momento, los servicios estatales están elaborando el Plan de Prévention du Risque d'Inondation (PPRi), cuyo objetivo es limitar la extensión urbana en la zona inundable. Aunque este documento 
Mapa 7. Zonificación reglamentaria del Plan d'Occupation des Sols (POS) de 1982

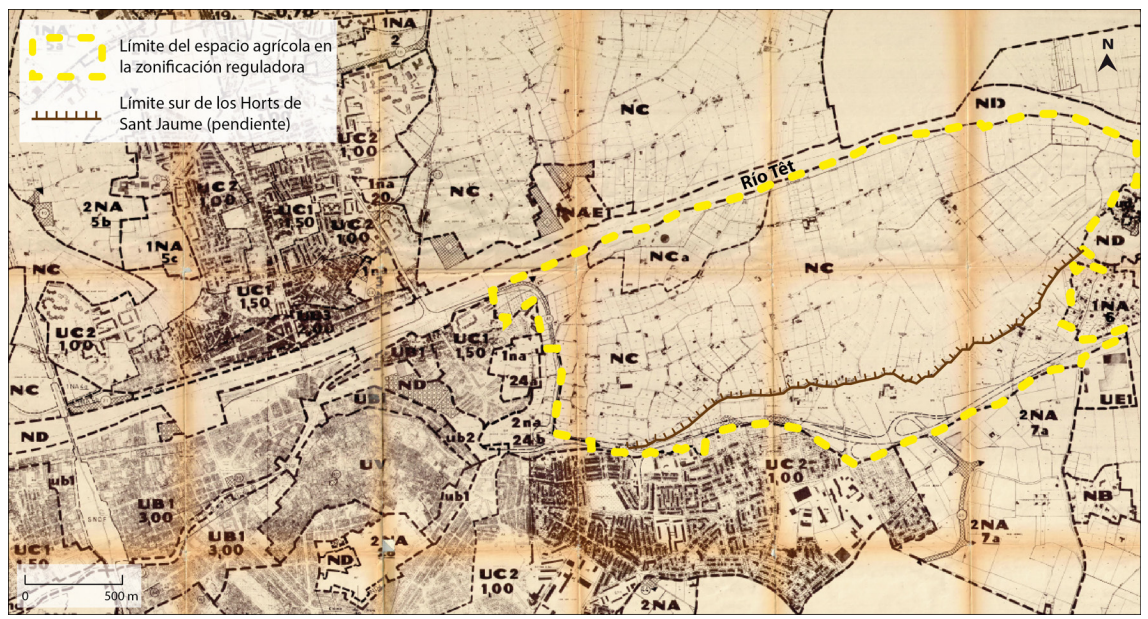

Fuente: elaboración propia a partir del Plan d'Occupation des Sols (POS) de 1982.

Mapa 8. Zonificación reglamentaria del Plan d'Occupation des Sols (POS) de 1998

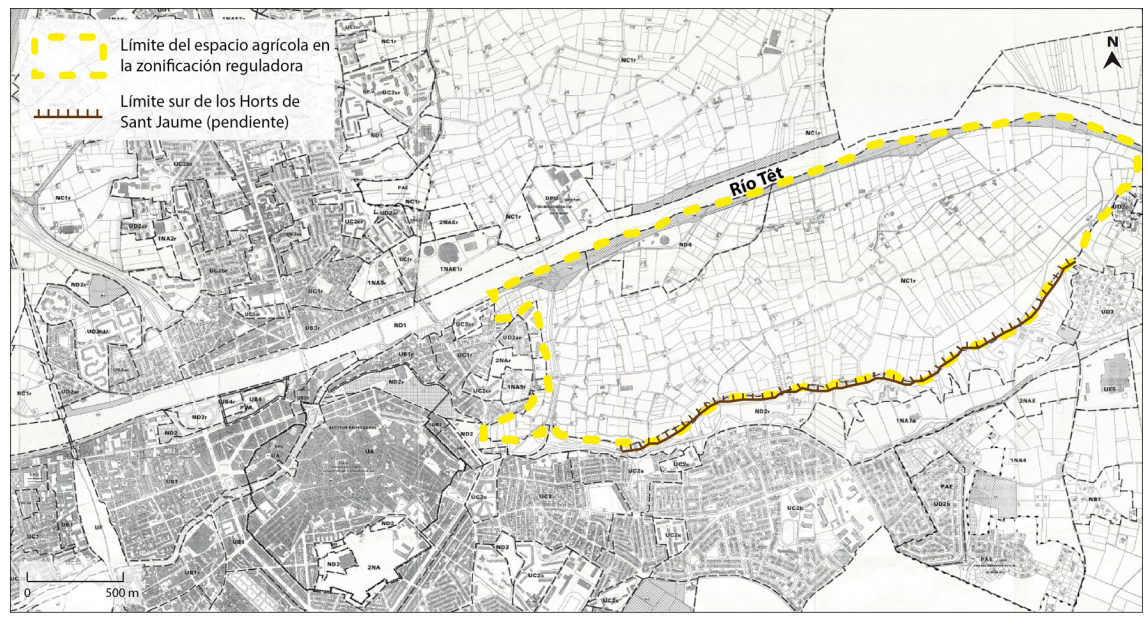

Fuente: elaboración propia a partir del Plan d'Occupation des Sols (SOS) de 1998.

se validó de forma oficial en el año 2000, los servicios estatales solicitaron al consistorio de Perpinyà que tuviera en cuenta este riesgo en la elaboración del Plan. A partir de esa coyuntura, los Horts de Sant Jaume se benefician - por así decirlo- de una doble protección con respecto a la urbanización: su clasificación, por un lado, como «zona agrícola» en la planificación de ámbito municipal y, por otro, como zona de «alto» $\mathrm{y}$ «muy alto riesgo de inundación» 
en buena parte de su perímetro; una clasificación, esta última, que prohíbe expresamente cualquier tipo de urbanización. En la misma línea, el Plan Local d'Urbanisme (PLU), en sus versiones de 2007 y 2016, clasifica a los Horts de Sant Jaume como zona «A1r», es decir, una zona agrícola sometida a un riesgo de inundación alto.

Más allá de las diferencias en la clasificación "por zonas» por parte de las diferentes generaciones de planes, hay aquí un hecho, a nuestro modo de ver, especialmente relevante: el ámbito de los Horts de Sant Jaume es reconocido sistemáticamente en su vocación agrícola, y todos los documentos de planificación urbana pretenden protegerlo y perpetuarlo. Si bien la proximidad al centro de Perpinyà podría haber provocado una fuerte presión sobre el suelo de cara a su urbanización, tal circunstancia no se llegó a producir. Si consideramos una franja temporal más amplia en el contexto de desarrollo urbano de Perpinyà, encontramos otra explicación complementaria: la urbanización preferente del sector oeste de su término municipal durante la segunda mitad del siglo XIX — después de la implantación de la estación ferroviaria al oeste de la ciudad fortificada-, así como también hacia el norte en la primera mitad del siglo xx y, finalmente, hacia el sur a partir de mediados del siglo xx.

En cambio, en el sector este del municipio nunca se ha auspiciado el crecimiento urbano. De hecho, el primer documento de planificación moderno de la ciudad (el llamado Plan Dervaux, adoptado en 1927) no contemplaba la urbanización de los Horts de Sant Jaume - aunque existió la previsión de un desarrollo urbano de este espacio por parte del consistorio, elaborada en 1936 y aprobada en 1940, nunca llegó a aplicarse (De Roux, 2014)—. Finalmente, el Schéma de cohérence territoriale de la Plaine du Roussillon, un documento de planificación supracomunal adoptado en 2013, también confiere protección a nuestro ámbito de estudio a través de su clasificación como «espacio agrícola con un alto potencial» y como "zona agropecuaria». Estas dos clasificaciones comparten un mismo principio de «no constructibilidad» -incluso para las plantas de energía solar-, y su objetivo principal es la preservación del potencial agrícola.

Sin embargo, esta persistente protección del perfil agrícola de nuestra área de estudio a través de los documentos de planificación no impide la emergencia de ciertas formas de presión urbanística y de cambio de uso del suelo, lo cual supone una coyuntura desfavorable para las edificaciones existentes. En 1999 se inauguró una vía rápida de 11 kilómetros y dos carriles (la llamada "carretera provincial 617») entre Perpinyà y la cercana ciudad costera de Canet (esto es, Canet-en-Roussillon). Esta infraestructura, que se extiende a lo largo del Tet, en el límite norte de los Horts de Sant Jaume, contribuye a separar esa zona hortícola del área fluvial. En 2008 se puso en marcha una planta de tratamiento de aguas residuales intermunicipales ubicada en el perímetro de nuestra área de estudio, concretamente en el borde de la D617 (mapa 9). Esta infraestructura, de grandes dimensiones, ha contribuido a la urbanización de una pequeña parte de las tierras agrícolas de la zona. Otra amenaza, más 
Mapa 9. Zonificación reglamentaria del Plan Local d’Urbanisme (PLU) de 2016

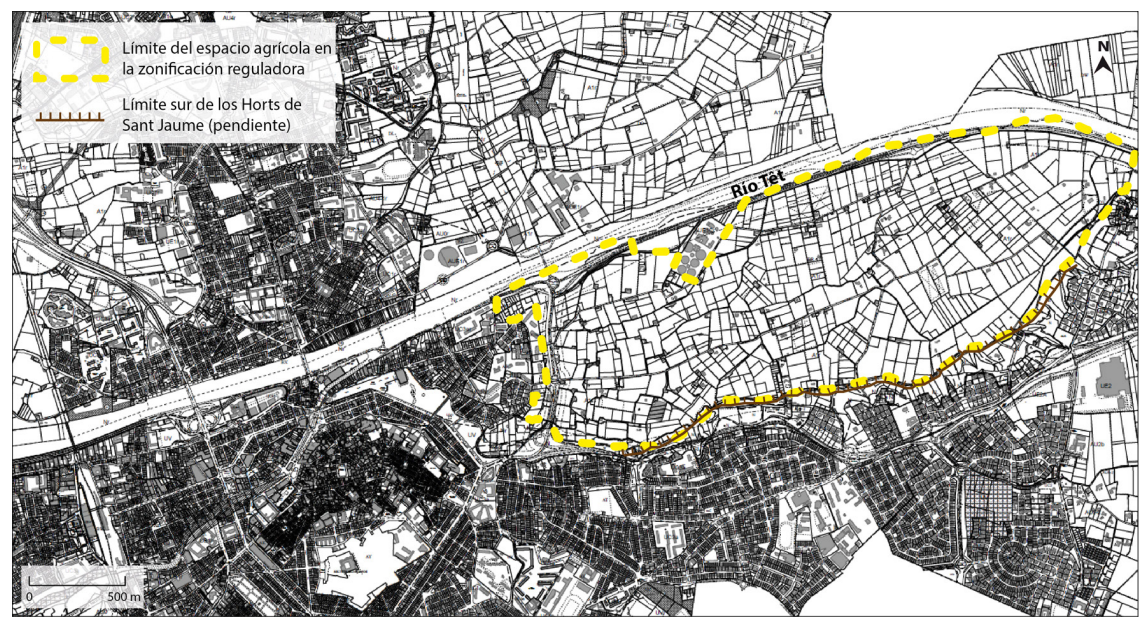

Fuente: elaboración propia a partir del Plan Local d’Urbanisme (PLU) de 2016.

difusa, atañe a la solicitud de permisos de construcción para edificios que no estén relacionados con la actividad agrícola. Dicha solicitud constituye un requisito sine qua non para tener el derecho a construir un nuevo edificio o a ampliar uno que ya exista en esta zona. Finalmente, otro hecho importante a tener en cuenta es el escenario que se produce después de la jubilación de los horticultores, sobre todo en relación con la dificultad de encontrar un nuevo comprador, la voluntad de seguir con la actividad agrícola o la posibilidad de dedicar las parcelas a usos no agrícolas.

Ante estas amenazas y con el objetivo de mantener el destino agrícola del conjunto de los Horts de Sant Jaume, la Administración ha tratado recientemente de esbozar estrategias y políticas de paisaje para su desarrollo. En 2012, el consistorio de la ciudad y la Administración intercomunal Perpignan Méditerranée Communauté d'Agglomération firmaron un acuerdo para implementar «un proyecto piloto para el desarrollo económico y de ordenación», con el fin de "contextualizar y supervisar la conservación, la gestión y el desarrollo económico de los Horts de Sant Jaume enfatizando la dimensión ambiental del territorio y fortaleciendo la relación entre ciudad y campo» ${ }^{17}$. Este objetivo aún no se ha cumplido y nuestra área de estudio sigue siendo un espacio singular: una zona de producción intensiva de vegetales y un paisaje agrario a las puertas del centro urbano, habiendo resistido las diferentes fases de urbanización existentes — gracias, en particular, a la coherencia de la planificación urbana-, pero aún con múltiples potencialidades a desarrollar en relación con la ciudad.

17. Traducción de los autores (del francés al castellano). 


\section{Discusión y conclusiones}

A nuestro juicio, los tres paisajes agrarios analizados a lo largo del artículo presentan suficientes motivos para ser considerados, en su escala de referencia, como patrimoniales. Cumplen, en este sentido, los tres argumentos centrales que, desde una mirada experta, se conciben como necesarios para poder otorgar un valor patrimonial a los paisajes agrarios (Silva, 2009): han sido objeto de atención institucional a través de una variada tipología de planes y de instrumentos de planeamiento general o especial; son, en sí mismos, sujetos de una amplísima gama de valores y de significados, enraizada, en cada uno de los casos estudiados, en la "historia territorial» que les concierne (y que, a su vez, puede tener una dominante rural o urbana, o incluso ambas simultáneamente), $\mathrm{y}$, finalmente, actúan o han actuado, dentro de su ámbito de referencia respectivo, como «condensadores» o "catalizadores» de una determinada manera de ver o de entender el paisaje que, a la postre, ha hecho posible su apreciación (y, en cierta manera, su apropiación) en clave colectiva.

Conviene, en cualquier caso y en el contexto descrito, entender la patrimonialidad de los paisajes a que aludimos en un sentido "dinámico" antes que "estático», e interpretarla más como un "punto de partida» que como una «meta de llegada». En los tres casos los paisajes agrarios en cuestión acumulan, a diferentes niveles y con intensidades desiguales, problemáticas a las que el planeamiento no siempre es capaz de hacer frente y que, a buen seguro, se manifestarán dentro de un plazo no necesariamente corto. El abandono de la actividad agraria o la incierta sustitución de los agricultores actualmente en activo, o las dificultades para conciliar la multiplicidad de intereses en juego (convertida a menudo en entornos urbano-rurales de dinamismo económico creciente, en conflicto abierto) son ejemplos de circunstancias que, entre muchas otras, pueden hacer fracasar las mejores intenciones a la hora de plantear un escenario de continuidad.

En la práctica, y desde una óptica más concreta, el estudio llevado a cabo demuestra que los instrumentos de planificación urbana han sido útiles en la protección de los espacios agrarios analizados, pero no suficientemente ágiles en el desarrollo de estrategias de dinamización. Si bien cada caso de estudio se ha regido por una casuística particular, todos ellos comparten un hecho común: la revitalización de los espacios agrarios es una cuestión que solo a partir de las últimas décadas empieza a considerarse necesaria. La planificación urbana anterior a los años noventa no tiene en cuenta, de hecho, la problemática asociada a este tipo de espacios más allá de su protección. Así las cosas, su pervivencia física hasta la actualidad se debe más a una clasificación del suelo de concepción «estática» e «invariable» que a una identificación genuina de problemáticas como el abandono de la actividad agraria o el incremento de la marginalidad de los espacios agrarios periurbanos. En este sentido, que hablemos de una adscripción administrativa a España o Francia no cambia significativamente las cosas, puesto que, en esencia, los instrumentos de planificación urbana aprobados han seguido en el marco de un Estado o del otro la misma filosofía proteccionista. 
Las estrategias de dinamización son muy recientes y, además, sin una eficacia aún probada. En el caso de Lleida, estas estrategias siguen aún en debate a raíz del proceso de aprobación del último plan de ordenación urbana municipal (POUM). En el caso de Girona, se cuenta con planificación especial aprobada desde el año 2005, pero los frutos aún no se perciben con notoriedad. En el caso de Perpinyà, existe un compromiso político desde el año 2012 que, desafortunadamente, aún no se ha materializado. La mayor parte de iniciativas emanan de una cierta voluntad técnica y política de mantener la actividad hortícola y fomentar su desarrollo como espacio de ocio - e incluso turístico-. No puede haber duda de que la mera existencia de iniciativas, y su progresiva vertebración como anteproyectos, denota por sí misma una asunción progresiva de la problemática de fondo. Sin embargo, cabe subrayar por ahora que se trata, fundamentalmente, de estrategias que requieren dosis importantes de concreción y una implementación que todavía no se ha producido. La lentitud de los procesos administrativos, conjuntamente a la necesidad de una estrategia a largo plazo, puede acabar representando un empeoramiento de las problemáticas inherentes a cada caso de estudio.

Por otra parte, es importante subrayar que la ambivalencia de los casos de estudio analizados - que comparten, en todos los casos, una dimensión agraria y otra de fluvial — les confiere una cualidad geográfica añadida: se trata de espacios que, en mayor o menor medida, presentan franjas inundables, de forma que su urbanización ha sido más compleja de llevar a cabo. En el caso de Lleida, y a raíz de la gran inundación de los años ochenta, la transformación urbana del espacio hortícola de la margen izquierda del Segre implicó el desarrollo del barrio de Cappont (aunque tal desarrollo no afectó de forma significativa el conjunto de la superficie hortícola municipal). En cambio, en los casos de Girona y Perpinyà, las políticas de desarrollo urbano y territorial se llevaron a cabo a partir de directrices diferentes, de manera que la doble condición agraria e inundable de los espacios concernidos no representó, en un primer momento, un buen tándem para la expansión urbana. Cabe añadir, por otra parte, que la condición fluvial de estos espacios comporta la presencia de otros valores, de carácter eminentemente social, que, sumados a las estrategias de dinamización que se han llevado a cabo en los últimos años, pueden resultar muy interesantes de cara al futuro. En este sentido, es indudable que la actividad turística, deportiva y recreativa puede representar un acicate para la promoción, en los espacios de referencia, de estrategias de acción integrada que tengan en cuenta la relevancia del contexto territorial.

En resumen, tal y como hemos visto a lo largo del artículo, la protección - presente, de una u otra forma, en los tres espacios agrofluviales estudiadosno es suficiente por sí misma para asegurar su permanencia en el espacio y en el tiempo y, a su vez, evitar su degradación futura. La necesidad de superar el riesgo de una dicotomía estricta entre la visión «idealizada» y la visión «materialista» de lo rural no ha de impedirnos ver que el análisis crítico y las políticas activas, a múltiples niveles, pueden representar herramientas clave para abordar problemas de fondo como los que hemos expuesto. 
S. Rode; A. Santasusagna; La preservación de los espacios agrofluviales urbanos como reto paisajístico: un análisis

\section{Referencias bibliográficas}

Ajuntament de Girona [Ayuntamiento de Gerona] (1955). Plan General de Ordenación de la Inmortal Ciudad de Gerona y su zona de influencia. Girona: Ajuntament de Girona.

- (2002). Revisión del Plan General de Ordenación Urbana de Girona. Girona: Ajuntament de Girona.

- (2005). Pla especial de les hortes de Santa Eugènia. Recuperado el 21 de marzo de 2019, de <http://www.girona.cat/shared/admin/docs/p/l/pla_especial_hortes_sta_eugenia.pdf >.

Ajuntament de Lleida [Ayuntamiento de Lérida] (1958). Plan General de Ordenación Urbana. Lleida: Ajuntament de Lleida.

- (1994). Pla d'espais lliures de Lleida. Lleida: Ajuntament de Lleida.

- (2017). Pla d'usos de l'horta de Lleida. Lleida: Ajuntament de Lleida.

Aldomà Buixadé, Ignasi (dir.) (2008). L’horta de Lleida: Transformació i salvaguarda d'un espai periurbà. Ponències presentades en les jornades de març-abril 2007. Lleida: Universitat de Lleida.

- (2009). «Les dificultats de manteniment de l'agricultura periurbana: L'exemple de l'horta de Lleida». Scripta Nova: Revista Electrónica de Geografía y Ciencias Sociales, XIII, 284. Recuperado el 21 de marzo de 2019, de <http://www.ub.edu/geocrit/ sn/sn-284.htm>.

- (dir.) (2013). L'Horta, rebost i patrimoni de Lleida. Lleida: Ajuntament de Lleida.

Andrés SARASA, José Luis (2004). «Incertidumbres en el espacio agrícola y proceso urbanizador resort en la región de Murcia». Cuadernos de Turismo, 14, 7-66.

Bellet Sanfeliu, Carme (1994). "Activitat immobiliària a Lleida (1979-1989)». Documents d'Anàlisi Geogràfica, 25, 15-36.

- (2011). «La inserción de la universidad en la estructura y forma urbana: El caso de la Universitat de Lleida». Scripta Nova: Revista Electrónica de Geografía y Ciencias Sociales, XV, 381. Recuperado el 21 de marzo de 2019, de <http://www.ub.edu/ geocrit/sn/sn-381.htm>.

Corbera Millán, Manuel (2016). «El paisaje, su patrimonialización y el beneficio económico». Investigaciones Geográficas, 65, 9-24.

Cruz Villalón, Josefina y Silva Pérez, Rocío (2016). «Valor, percepción y regulación de paisajes y agriculturas periurbanas en Andalucía». En: Olcina, Jorge y Rico, Antonio M. (coords.). Libro jubilar en homenaje al profesor Antonio Gil Olcina. Alicante: Publicaciones de la Universidad de Alicante, 533-541.

De Roux, Antoine (2014). Perpignan. De la place forte à la ville ouverte, Xe-XXe siècle, Perpiñán: Editions Les Presses Littéraires.

Feito, María Carolina (2018). «Problemas y desafíos del periurbano de Buenos Aires». Estudios Socioterritoriales: Revista de Geografía, 24, 1-19.

Feixa PÀmpols, Carles (1993). «La ciutat de les cols: Memòria oral de l'horta». En: Pijuan, Josep y Aldomà Buixadé, Ignasi (coords.). L'horta de Lleida. Lleida: Ateneu Popular de Ponent, 41-59.

Frolova, Marina; Menor Toribio, José y Cancer Pomar, Luis (2003). «El paisaje en las políticas públicas de Francia y España: Desde la protección del monumento a la gestión del espacio». Estudios Geográficos, 64 (253), 605-622.

Galacho-Jiménez, Federico Benjamín y Luque-Gil, Ana (2000). «La dinámica del paisaje de la Costa del Sol desde la aparición del turismo». BAETICA: Estudios de Historia Moderna y Contemporánea, 22, 25-58.

GANAu, Joan (1992). La idea de ciutat a Lleida. Lleida: Pagès Editors. 
Gómez Mendoza, Josefina (2013). «Del patrimonio-paisaje a los paisajes-patrimonio». Documents d'Anàlisi Geogràfica, 59 (1), 5-20. <https://doi.org/10.5565/rev/dag.48>

Hernández Hernández, María y Morales Gil, Alfredo (2012). «Patrimonio agrario: Paisaje y cultura en las riberas del Mediterráneo». En: BARCiela López, Carlos; López Ortiz, María Inmaculada y Melgarejo Moreno, Joaquín (coords.). Los bienes culturales y su aportación al desarrollo sostenible. Alicante: Servicio de Piblicaciones de la Universidad de Alicante, 263-290.

Ibarra Benlloch, Paloma et al. (2011). «La problemática de los parques eólicos en las áreas administrativas limítrofes: Beneficio económico frente a degradación paisajística». En: Gozálvez Pérez, Vicente y Marco Molina, Juan Antonio (coords.). Geografía y desafíos territoriales en el siglo XXI. Alicante: Asociación de Geógrafos Españoles, 177-190.

Lasanta Martínez, Teodoro; Arnáez, José; Ruiz Flaño, Purificación y LanaRenault Monreal, Noemí (2013). «Los bancales en las montañas españolas: Un paisaje abandonado y un recurso potencial». Boletín de la AGE, 63, 301-322.

LLOP-Torné, Carles (2011). "La valorización y dinamización de los paisajes y el desarrollo económico local». En: Simancas Cruz, Moisés y Cortina Ramos, Albert (coords.). Retos y perspectivas de la gestión del paisaje en Canarias: Reflexiones en relación con el $10^{\circ}$ aniversario de la firma del Convenio Europeo del Paisaje. Tenerife: Gobierno de Canarias, Universidad Internacional Menéndez Pelayo, 413-436.

- (coord.) (1995). Atles urbanistic de Lleida 1707-1995. Lleida: Ajuntament de Lleida, Col.legi d'Arquitectes de Catalunya.

Llop-Torné, Josep Maria et al. (2002). «El río Segre, eje del Plan de Espacios Libres en Lleida». En: Cal, Pedro de la y Pellicer, Francisco (coords.). Ríos y ciudades: Aportaciones para la recuperación de los rios y riberas de Zaragoza. Zaragoza: Institución Fernando el Católico, 77-96.

Mata Olmo, Rafael (2004). «Agricultura, paisaje y gestión del territorio». Polígonos: Revista de Geografía, 14, 97-137.

Mata Olmo, Rafael y Tarroja Coscuela, Alexandre (2006). El paisaje y la gestión del territorio: Criterios paisajisticos en la ordenación del territorio y el urbanismo. Barcelona: Diputació Provincial de Barcelona.

Matarán-Ruiz, Alberto (2013). «El paisaje como alternativa a los procesos de desterritorialización en Andalucía». En: CAMAcho Ballesta, José Antonio y JimÉnez Olivencia, Yolanda (coords.). Desarrollo regional sostenible en tiempos de crisis. Granada: Universidad de Granada, 225-234.

Mayoral Arqué, Dolors (1993). «Els homes i dones de l'horta de Lleida: Breu aproximació sociològica». En: Pijuan, Josep y Aldomà Buixadé, Ignasi (coords.). L'horta de Lleida. Lleida: Ateneu Popular de Ponent, 25-40.

Millán Vásquez de la Torre, María Genoveva; Amador Hidalgo, Luis y Arjona Fuentes, Juan Manuel (2015). «El oleoturismo: Una alternativa para preservar los paisajes del olivar y promover el desarrollo rural y regional de Andalucía (España)». Revista de Geografía Norte Grande, 60, 195-214.

Molinero Hernando, Fernando (2011). «Los paisajes del viñedo en Castilla y León: Tradición, renovación y consolidación». Polígonos: Revista de Geografía, 21, 85-117.

Mulero Aparicio, Antonio (2016). «Córdoba y el Guadalquivir: Hacia la recuperación del espacio fluvial en el entorno monumental de la ciudad». En: Olcina, Jorge y Rico, Antonio M. (coords.). Libro jubilar en homenaje al profesor Antonio Gil Olcina. Alicante: Publicaciones de la Universidad de Alicante, 327-341. 
NoguÉ Font, Joan (2007). «Paisaje, identidad y globalización». Fabrikart: Arte, Tecnología, Industria, Sociedad, 7, 136-145.

- (2010a). «El paisaje en la ordenación del territorio: La experiencia del Observatorio del Paisaje de Cataluña». Estudios Geográficos, 71 (269), 415-448.

- (2010b). «El retorno al paisaje». Enrahonar: Quaderns de Filosofia, 45, 123-136. <https://doi.org/10.5565/rev/enrahonar.224>

PaÜL CARril, Valerià (2010). «El cambio en los usos agrarios del suelo en el actual ámbito metropolitano de Barcelona (del siglo Xviı a la actualidad)». Investigaciones Geográficas, 53, 145-188.

Paül Carril, Valerià y Haslam McKenzie, Fiona (2013). «Peri-urban farmland conservation and development of alternative food networks: Insights from a case-study area in metropolitan Barcelona (Catalonia, Spain)». Land Use Policy, 30 (1), 94-105.

Paül Carril, Valerià; Tort Donada, Joan y Sancho Reinoso, Alexis (2011). «El marco conceptual de los paisajes de la agricultura». En: Molinero, Fernando; TorT, Joan y OjedA, Juan Francisco (coords.). Los paisajes agrarios de España: Caracterización, evolución y tipificación. Madrid: Ministerio de Medio Ambiente y Medio Rural y Marino, 9-38.

Pellicer Corellano, Francisco y Ollero Ojeda, Alfredo (2004). «Agua y ciudad». Boletín de la AGE, 37, 3-13.

Prada Llorente, Esther Isabel (2005). «Paisaje agrario: Antropología de un territorio». Ciudad y Territorio: Estudios Territoriales, 144, 343-372.

Ribas Palom, Anna (2001). «Girona, ciutat fluvial». Annals de l'Institut d'Estudis Gironins, 42, 11-24.

- (2007). «Los paisajes del agua como paisajes culturales: Conceptos, métodos y una experiencia práctica para su interpretación y valorización». Apogeo: Revista da Associação de Professores de Geografia, 32, 39-48.

Rubert TayÀ, Júlia (2005). «Pla urbanístic dels horts de Santa Eugènia (Girona i Salt)». Territori: Observatori de projectes $i$ debats territorials de Catalunya. Recuperado el 21 de marzo de 2019, de <http://territori.scot.cat/cat/notices/pla_urbanIstic_dels_horts_de_santa_eugEnia_girona_i_salt_2005_862.php >.

Sancho Reinoso, Alexis; Paül Carril, Valerià y Tort Donada, Joan (2013). «Paisajes agrarios en conflicto: El caso de la floricultura en el Baix Maresme (Barcelona)». Scripta Nova: Revista Electrónica de Geografía y Ciencias Sociales, 17, 425-462.

Santasusagna Riu, Albert y Tort Donada, Joan (2019). "Agua y espacio urbano: Algunas consideraciones teóricas a propósito de la relación entre ciudad y río». Documents d'Anàlisi Geogràfica, 65 (2), 371-397. $<$ https://doi.org/10.5565/rev/dag.513>

Santiago Rodríguez, Eduardo de (2012). «Una lectura de las políticas de suelo y los modelos urbanísticos madrileños desde mediados de los años 1990: De la liberalización a la resaca inmobiliaria». Geopolitica(s): Revista de Estudios sobre Espacio y Poder, 3 (1), 83-116.

Serrano Giné, David (2007). «Paisaje y políticas públicas». Imvestigaciones Geográficas, 42, 109-123.

Silva PÉrez, Rocío (2009). «Agricultura, paisaje y patrimonio territorial: Los paisajes de la agricultura vistos como patrimonio». Boletín de la AGE, 49, 309-334.

Silva Pérez, Rocío y Fernández Salinas, Víctor (2017). «El nuevo paradigma del patrimonio y su consideración en los paisajes: Conceptos, métodos y prospectivas». Documents d'Anàlisi Geogràfica, 63 (1), 129-151. <https://doi.org/10.5565/rev/dag.344> 
Sureda Canals, Pere Joan (2002). «Les centrals elèctriques de la sèquia Monar». Revista de Girona, 213, 70-75.

Tarroja Coscuela, Alexandre (2006). «Transformaciones territoriales y valoración social del paisaje». En: Mata Olmo, Rafael y Tarroja Coscuela, Alexandre (coords.). El paisaje y la gestión del territorio: Criterios paisajisticos en la ordenación del territorio y el urbanismo. Barcelona: Diputación Provincial de Barcelona, 41-50.

Torre, André y Bourdeau-Lepage, Lise (2013). «Quand l'agriculture s'installe en ville...: Désir de nature ou contraintes économiques?». Métropolitiques. Recuperado el 28 de marzo de 2019, de <http://www.metropolitiques.eu/Quand-l-agriculture-s-installe-en.html>.

VidAl, Roland y Fleury, André (2009). «La place de l'agriculture dans la métropole verte: Nostalgies, utopies et réalités dans l'aménagement des territoires aux franges urbaines». Projet de paysage, 1. Recuperado el 28 de marzo de 2019, de <https:// www.projetsdepaysage.fr/la_place_de_l_agriculture_dans_la_metropole_verte>.

Zoido Naranjo, Florencio (2001). «La Convención Europea del Paisaje y su aplicación en España». Ciudad y Territorio: Estudios Territoriales, 128, 275-282.

- (2010). «Territorio y paisaje, conocimiento, estrategias y políticas». En: Pillet Capdepón, Félix; Cañizares Ruiz, María del Carmen y Ruiz Pulpón, Ángel Ruiz (coords.). Territorio, paisaje y sostenibilidad: Un mundo cambiante. Barcelona: Ediciones del Serbal, 85-112. 